\title{
New Opportunities in Heterogeneous Catalysis
}

\author{
DINESH JAGADEESAN ${ }^{1, *}$, DNYANESH VERNEKAR ${ }^{2}$, SHARAD GUPTA $^{3}$ and GARIMA JAISWAL ${ }^{4}$ \\ ${ }^{1}$ Department of Chemistry, Indian Institute of Technology Palakkad, Kozhippara, Palakkad 678 557, \\ Kerala, India \\ ${ }^{2}$ Chemical Engineering and Process Development Division, CSIR-National Chemical Laboratory, Pashan, \\ Pune 411 008, Maharashtra, India \\ Academy of Scientific and Innovation Research (ACSIR), Ghaziabad 201 002, India \\ ${ }^{3}$ Inorganic Chemistry and Catalysis Division, CSIR-National Chemical Laboratory, Pashan, Pune 411 \\ 008, Maharashtra, India \\ Academy of Scientific and Innovation Research (ACSIR), Ghaziabad 201 002, India \\ ${ }^{4}$ Organic Chemistry Division, CSIR-National Chemical Laboratory, Pashan, Pune 411 008, Maharashtra, \\ India \\ Academy of Scientific and Innovation Research (ACSIR), Ghaziabad 201 002, India
}

(Received on 02 May 2018; Revised on 10 July 2018; Accepted on 11 August 2018)

\begin{abstract}
Nearly $80 \%$ of the processes involved in the chemical production of bulk or fine chemicals employ heterogeneous catalysts that are typically solids. The heart of the heterogeneous catalyst is the surface active site which must be highly active, selective and stable during several hundred cycles of reaction. Although it is not always possible to determine the structure of an active site in a heterogeneous catalyst, the emphasis of modern day research has not only been to understand the structure of an active site but also synthesize and study them. The article will describe some of the challenges from this perspective with examples from the authors research.
\end{abstract}

Keywords: Heterogeneous Catalysis; Multifunctional Catalysts; Hydrogenation; Dehydrogenation

\section{Introduction}

Catalysts are defined as chemical substances that transform reactants to products through uninterrupted and repeated cycles of elementary steps in which the catalyst is regenerated to its original form by the end of a cycle. Catalysts bind with reactants in a specific manner and cause an accelerated rate of transformation to products by lowering the activation energy. Heterogeneous catalysis involves studies of catalysts that are in a physical phase different from that of reactants and products. Typically, heterogeneous catalysts are solids, while the reactants and products are liquids or gases or a mixture of both. Heterogeneous catalyst science and technology is a matured branch in chemistry with several pivotal contributions to major economic transformations in the human history. For example, iron oxide catalyst promoted with $\mathrm{K}_{2} \mathrm{O}, \mathrm{CaO}, \mathrm{SiO}_{2}$ or $\mathrm{Al}_{2} \mathrm{O}_{3}$ was used to produce fertilizers by converting $\mathrm{N}_{2}$ to $\mathrm{NH}_{3}$. This reaction helped quadruple the productivity of agricultural lands which was desperately needed during the world war (Jacobsen et al., 2001). Another important example is the refining of crude oil by hydrocracking, hydrodesulfurization, hyrodenitrogenation, hydrodechlorination over Mo based catalysts and zeolite catalysts to produce useful distillates. This reaction was responsible for the large scale production of fuel grade gasoline and diesel in addition to several low molecular weight hydrocarbons and aromatic compounds useful in chemical industry (Matar et al., 1998). Besides large scale production of fuels and chemicals, heterogeneous catalysts are also extensively used in automobiles in catalytic converters

*Authorfor Correspondence: E-mail:d.jagadeesan@iitpkd.ac.in 
that treat $\mathrm{CO}$, unburnt hydrocarbons and $\mathrm{NO}_{\mathrm{x}}$ from the engine exhausts to a less harmful composition. The ease of separation from the reaction mixture and robustness even under very harsh reaction conditions have given heterogeneous catalysts a competitive edge over its homogeneous counterparts (Khosla, 1997; Leadlay, 1997; Staunton and Wilkinson, 1997; Townsend, 1997; Bew et al., 2015). Heterogeneous catalysts are very promising candidates to address emerging problems ranging from indoor sensors, purifiers to photocatalytic $\mathrm{H}_{2}$ production.

The most important aspect of a heterogeneous catalyst is the active sites (or active centers) at the surface of the solid. The active site could be a specific crystallographic plane of the solid with an surface atoms in an under co-ordination environment, a defect in the crystallographic phase such as a vacancy, surface composition or an interface between metal and support (Gao et al., 2016; Chen G 2016). The electron density at the active sites are usually different from rest of the surface affecting the chemisorption of the reactant and product molecules at these sites. The heterogeneous catalyst is typically a high-surface area material (e.g., $10-1000 \mathrm{~m}^{2} \mathrm{~g}^{-1}$ ), and it is usually desirable to maximize the number of active sites per reactor volume. A successful heterogeneous catalyst is a product of fine optimization of physical and electronic structure leading to an enhanced stability and performance. Such catalysts are characteristic of high turnover numbers (defined as the number of reactant molecules transformed per gram of the catalyst in a unit time), high selectivity, cost effectiveness, high stability and maximum reusability. Current research efforts in heterogeneous catalysis are focused on the understanding and development of highly selective chemical active sites on the surface of the catalyst. The challenge is not only to identify the most suitable active site on the catalyst for a reaction but also ensure its abundance and stability on the surface of the catalyst throughout the reaction.

In the current global scenario, development of sustainable catalysts for reactions that are highly relevant to the production of bulk or fine chemicals, pharmaceutical products, fuels and materials are receiving greater attention. In addition, raising concerns about the overall economy of a chemical process, environmental benignity and carbon foot print presses new demands on catalysts. This review article will present some of the works of the authors in heterogeneous catalysis at CSIR National Chemical Laboratory in Pune in recent years (2013-2018). The review will highlight some of the important research outcomes related to the chemistry of catalyst materials in an attempt to address some of the emerging challenges mentioned above. The review is divided into three section. In the first section, our work related to multifunctionality in catalysts are discussed. Next generation catalysts are expected to have multiple catalytic sites on the same solid so that many reactions may be carried out in tandem. In the second section, we describe our attempts to produce single atom catalysts for organic transformation. We also discovered that unprecedented catalytic behavior could be observed by tuning the microstruture of the catalyst. In the last section, we describe our work related to Iron carbon alloy catalysts for hydrogenation of $\mathrm{CO}_{2}$. The article provides a brief background in each of the works, novelty of the approach, detailed discussion of the materials and future challenges. The article is written in the light of challenges in catalyst materials in the context of different kinds of reactions.

\section{Multi-functional Catalysts}

Multi-step reactions are often encountered in organic synthesis wherein catalysts are required for each step of a reaction in the sequence. Sometimes, the catalysts required in successive steps of a sequence could not only be different but also chemically incompatible with each other (e.g. acid and base). In such cases, a traditional organic synthesis methodology would recommend several work up steps resulting in poor catalytic effect, low yield and 'low quotient' on greenness of the process. Achieving such sequential transformations in tandem is definitely an effective approach to overcome the problem. However, such tandem reactions will demand a catalyst with multiple catalytic functional sites on it. Each functional site must be capable of catalyzing at least one of the several steps in the synthetic sequence. Importantly, the catalytic sites must be spatially isolated and not interfere with the catalytic action of the other sites. One can imagine that a multifunctional catalyst can conveniently transform a synthetic intermediate into a desired product by pushing it into a subsequent catalytic cycle ultimately leading to the final desired product. Thus, the process intensification is achieved without isolating an unstable or toxic synthetic 
intermediate (Tietze, 1996; Stankiewicz and Moulijn, 2000; Nicolaou et al., 2006; Van Gerven and Stankiewicz, 2009; Dhakshinamoorthy et al., 2014). Synthesis and applications of multifunctional catalysis is therefore an important area of research. Several recent reviews deal with the applications of multifunctional heterogeneous catalysts in tandem organic transformations (Huh et al., 2005; Margelefsky et al., 2008; Motokura et al., 2008; Corma et al., 2010; Liu et al., 2012; Diaz et al., 2013; $\mathrm{Xu}$ et al., 2014; Jagadeesan, 2016).

Development of a multifunctional catalyst involve a careful choice of catalytic active sites required for the entire sequence of the transformation. Following this, a synthesis scheme needs to be designed to introduce the reactive sites on a solid. The ability of a multifunctional catalyst is usually tested by studying the conversion and selectivity in a twostep sequential transformation, for example, first step needs an acid catalyst and the second step needs a base catalyst. In fact, materials based on this idea were proven to be efficient to carry out sequential transformations in a single pot (Huh et al., 2005). Ironically, the chemical approaches employed to introduce multiple functionalities on a catalyst themselves involved multiple steps involving surface functionalization, chemical protection and deprotection steps (Huh et al., 2005; Margelefsky et al., 2008; Motokura et al., 2008; Corma et al., 2010; Liu et al., 2012; Diaz et al., 2013; Xu et al., 2014; Jagadeesan, 2016).

In this context, our group demonstrated for the first time the acid-base bifunctional reactivity in metastable transition metal oxyhydroxide phases (MOOH where $\mathrm{M}$ is usually a transition metal). In our opinion, inorganic metastable phases such as $\mathrm{MOOH}$ are ideal as they are robust, inexpensive and easily scalable materials. These materials are usually prepared by hydrolytic sol-gel methods and can be considered as intermediates between hydroxylated metal sol precursors and completely condensed dense oxide phases (Cornell and Schwertmann, 2004). The functional groups $-\mathrm{OH}$ and their deprotonated conjugate base $-\mathrm{O}^{-}$groups are present in abundance on the surface and on the interiors of the materials exhibiting acidic and basic properties, respectively. Hence, the advantage with these materials is that there is no need for any surface functionalization to impart acidic and basic bifunctional catalytic activity (Jolivet et al., 2000; Yan et al., 2014; Smith et al., 2016). Interestingly, the surface hydroxyl groups on $\mathrm{MOOH}$ surface can exist in three different coordinated states. Under normal conditions $\mathrm{MOOH}$ surface can exist as 1) singly ( $\equiv \mathrm{MOH},-\mathrm{OH}) 2$ ) doubly $\left(\equiv \mathrm{M}_{2} \mathrm{OH}, \mu\right.$ $\mathrm{OH})$ and triply coordinated $\left(\equiv \mathrm{M}_{3} \mathrm{OH}, \mu_{3}-\mathrm{OH}\right)$ (Song et al., 2013). MOOH usually exists in multiple polymorphs such as $\alpha, \beta, \gamma, \delta$ which arises due to difference in arrangement of $\mathrm{M}(\mathrm{O})_{6}$ octahedra structural unit. These polymorphs have different crystal structure, morphology and also differ in densities of surface hydroxyl groups. One may expect the $p K_{a}$ values of each of the $-\mathrm{OH}$ and $-\mathrm{O}^{-}$species to be different depending on the coordination as well as structural arrangement of the basic structural unit giving rise to the possibility of tunable bifunctional property.

$\mathrm{MOOH}$ is an interesting class of material containing abundant surface hydroxyl groups than metal oxides along with M-O-M linkages and are more stable than Metal hydroxides. $\mathrm{MOOH}(\mathrm{M}=\mathrm{Fe}, \mathrm{Co}$, $\mathrm{Ni}, \mathrm{Mn}, \mathrm{Cr} \& \mathrm{Al}$ ) have been widely explored for a variety of applications. For example, $\mathrm{FeOOH}$ and $\mathrm{AlOOH}$ have been used for adsorption of toxic metals, anions from water sources (Ostergren et al., 1999, Horanyi et al., 2003). $\mathrm{CrOOH}$ and $\mathrm{FeOOH}$ used as precursors for pigments due to their green, orangebrown colour (Liang et al., 2014). $\mathrm{CoOOH}, \mathrm{NiOOH}$, $\mathrm{FeOOH}$ and a composite of these are extensively used for electrochemical applications such as Oxygen Evolution Reactions, Hydrogen Evolution reactions, supercapacitors and photochemical water splitting (Trotochaud et al., 2014, Lim et al., 2015, Feng et al., 2016, Huang et al., 2016, Kim et al., 2016). The predominant advantage of using $\mathrm{MOOH}$ for these applications is due to the nano size and presence of dissociable hydroxyl groups. However, $\mathrm{MOOH}$ as active catalyst for organic transformations has been not studied so far except for the use of $\mathrm{AlOOH}$ as a passive support for organic reactions where $-\mathrm{O}_{3} \mathrm{H}$ functionalized $\mathrm{SiO}_{2}$ was coated on $\mathrm{AlOOH}$ (GhorbaniChoghamarani et al., 2016). Another example used $\mathrm{AlOOH}$ as a support for Pt nanoparticles for formaldehyde synthesis, where the surface hydroxyl groups of $\mathrm{AlOOH}$ help in adsorbing the reactant molecules (Xu et al., 2015). We explored $\mathrm{MOOH}$ as an active material for acid-base bifunctionality, redox base bifunctionality and compared them with those 
available in literature which often require complex functionalization or use of expensive noble metals. Our work brings out the novel bifunctional aspect of Metal Oxyhydroxides and emphasizes a better substitute for the present state of art catalysts.

\section{Acid-Base Bifunctional Catalytic Activity}

MOOH $(\mathrm{M}=\mathrm{Fe}, \mathrm{Co}, \mathrm{Mn}, \mathrm{Cr}$ and $\mathrm{Al})$ were synthesized by "Soft Chemistry" routes at room temperatures or less than $300^{\circ} \mathrm{C}$ in hydrothermal process. Experimental parameters such as concentration, $\mathrm{pH}$, temperature, nature of anions can be modified to control size, texture and purity of various polymorphs in high yields. They are intermediates between metal hydroxides and highly condensed metal oxides. Metal is in trivalent state and surrounded by three $\mathrm{O}^{2-}$ and three $\mathrm{OH}^{-}$thereby making $\mathrm{M}(\mathrm{O})_{6}$ octahedra as the basic structural unit. The $\mathrm{MO}(\mathrm{OH})$ has surface hydroxyl groups as in metal hydroxides along with condensed M-O-M linkages found similar in metal oxides. The structure offers $\mathrm{MOOH}$ stability as well as reactivity making it an interesting catalyst.

The crystalline nature of $\mathrm{MOOH}$ materials were characterized using X-ray Diffraction. The polymorphs were identified using Infrared absorption spectra. The microstructure of the materials were studied under Transmission Electron Microscopy. Surface acidic and basic sites were studied using Temperature Programmed Desorption of $\mathrm{CO}_{2} / \mathrm{NH}_{3}$ and IR absorption spectra of the samples adsorbed with pyridine. We tested the materials for a model acid catalyzed deacetylation reaction followed by a base catalyzed condensation reaction in a single pot to probe the behavior of these solids (Fig. 1).
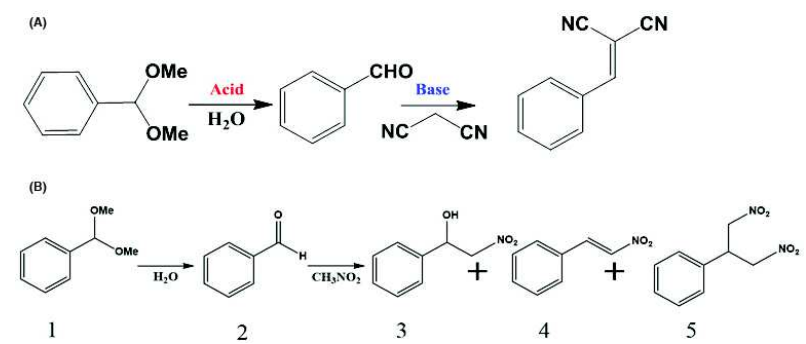

Fig. 1: Equations of acid-base catalyzed reactions (A) Deacetylation-Knoevenagel reaction (B) Deacetalization-Henry reaction
In Fig. 2, the general mechanism of acid- base reaction on a hypothetical $\mathrm{MOOH}$ surface is represented. The reaction involving acid catalyzed hydrolysis of benzaldehyde dimethylacetal followed by base catalyzed condensation is carried out in the presence of $\mathrm{MOOH}$. In the first step, the surface of the metal oxyhydroxide surface gets deprotonated by externally added water. In the presence of acidic sites, benzaldehydedimethylacetal (1) gets protonated and proceeds via subsequent loss of $\mathrm{MeOH}$ molecules to form benzaldehyde (2). In the next step the deprotonated hydroxyl groups act as active bases to abstract protons from the active methylene malononitrile forming a carbanion, which attacks the adsorbed benzaldehyde molecule on the surface as shown, ultimately leading to benzylidenemalononitrile (3) by loss of water molecule.

Our group reported the bifunctional acid-base property in $\mathrm{FeOOH}$ for the first time and also the difference in the catalytic activity in different polymorphs of FeOOH (Vernekar and Jagadeesan, 2015). Acid-base bifunctional nature of $\mathrm{MOOH}$ was found to differ with respect to the polymorphs in the case of $\mathrm{FeOOH}$. We synthesized four polymorphs of FeOOH namely, $\alpha, \beta, \gamma$ and $\delta$. Bifunctional catalytic activity in $\mathrm{FeOOH}$ polymorphs were demonstrated in a tandem reaction deacetalization-Henry reaction in one-pot. The first step involved an acid catalyzed hydrolysis of benzaldehyde dimethylacetal to benzaldehyde and the second step was the base catalyzed condensation of benzaldehyde with nitromethane to give trans- $\beta$-nitrostyrene. Achemical

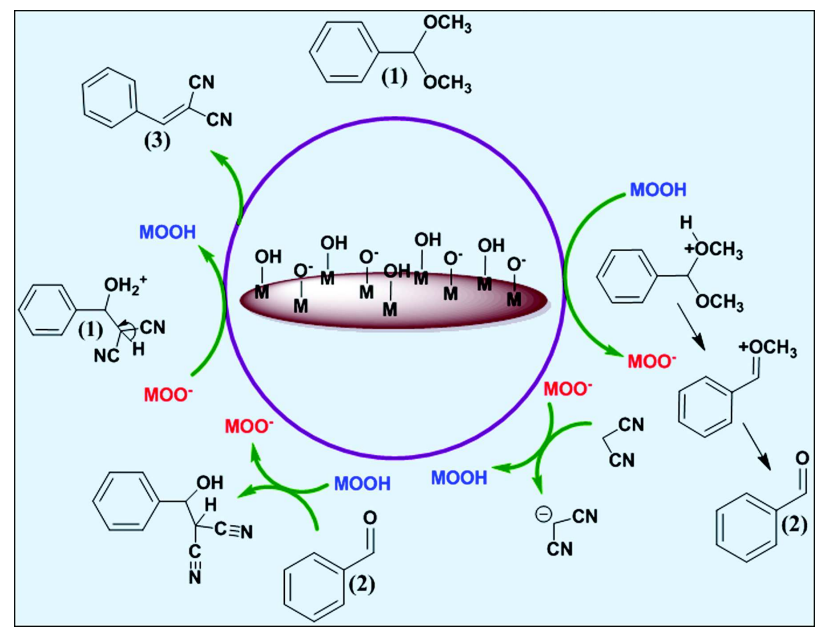

Fig. 2: The possible acid and base centers on metal hydroxides and metal oxyhydroxides 
(A)

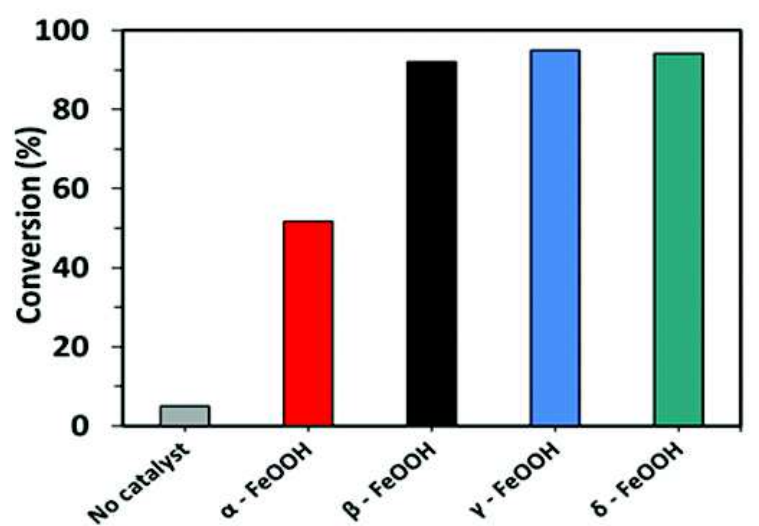

(B)

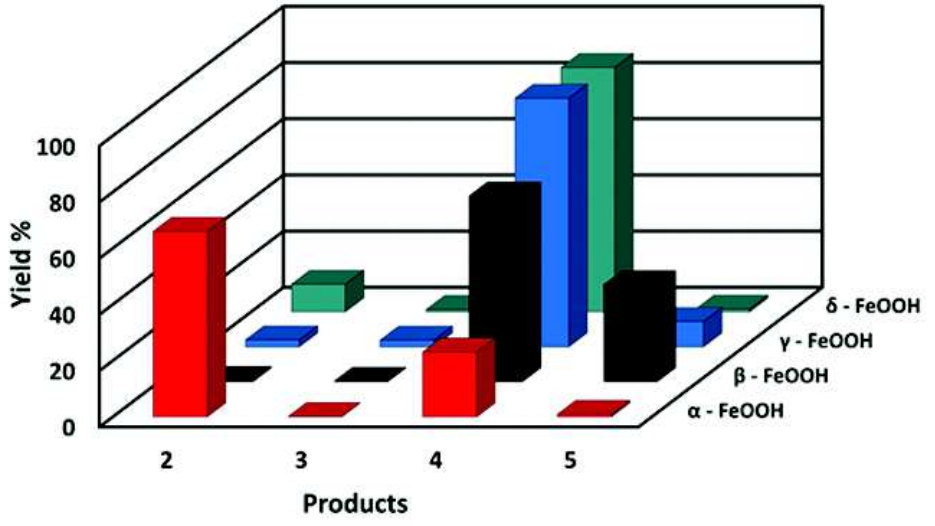

Fig. 3: (A) Conversion for the various polymorphs for deacetylation-Henry reaction (B) Yields of the products for the polymorphs. Reproduced by permission of The Royal Society of Chemistry

equilibrium between $\mathrm{OH}$ and $\mathrm{O}^{-}$groups on the surface of the catalysts was proposed as acidic and basic sites, respectively in the presence of $\mathrm{H}_{2} \mathrm{O}$ as shown in Eq. (1).

$$
\mathrm{FeOOH}+\mathrm{H}_{2} \mathrm{O} \leftrightarrow \mathrm{FeOO}^{-}+\mathrm{H}_{3} \mathrm{O}^{+}
$$

Difference in the density and strength of acidbase sites on the surface facets differed with polymorphs causing a difference in the catalytic activity. The $\mathrm{OH}$ group on the surface of $\mathrm{FeOOH}$ can either be single, doubly or triply coordinated to $\mathrm{Fe}$ atoms and hence lead to difference in the relative values of acidity and basicity. The four polymorphs of $\mathrm{FeOOH}(\alpha, \beta, \gamma$ and $\delta)$ exhibited different bifunctional activity towards the reaction (Fig. 3).

$\alpha-\mathrm{FeOOH}$ with a conversion of $50 \%$ behaved as a weak acid catalyst with a high selectivity to benzaldehyde. The other three polymorphs $(\alpha, \gamma$ and $\delta$ ) gave a conversion of more than $90 \%$ with a very high yield of trans- $\beta$-nitrostyrene. However $\beta$ $\mathrm{FeOOH}$ showed an odd behavior with the formation of a base catalyzed Michael addition product namely, trans- $\beta$-nitrostyrene with nitromethane to form a dinitro product indicating stronger basic sites. The chloride ions in the channels of $\beta-\mathrm{FeOOH}$ could be responsible for the dinitro product (3). The presence of water was found to be crucial to the formation of bifunctional sites on $\mathrm{FeOOH}$ as $\gamma$ $\mathrm{FeOOH}$ gave just $52 \%$ conversion in the absence of water as compared to $97 \%$ in the presence of water. Stability and recycle studies show the catalyst was stable even after five recycles and the activity was maintained.
The nature of acidic and basic sites were probed using pyridine IR and Hammett titrations. Pyridine being a base can get easily adsorbed to acid sites and can be identified using Infrared spectroscopy (Fig. 4).

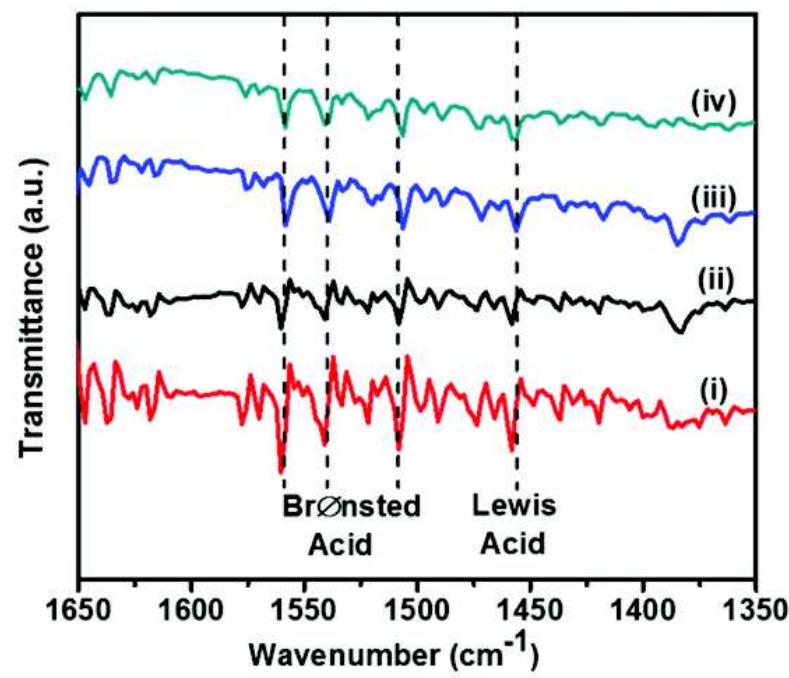

Fig. 4: Pyridine-IR data probing the acidic sites i) $\alpha-\mathrm{FeOOH}$ ii) $\beta$-FeOOH iii) $\gamma-\mathrm{FeOOH}$ and iv) $\delta$-FeOOH. Reproduced by permission of The Royal Society of Chemistry

All the polymorphs showed three prominent bands centered around 1560, 1541 and $1508 \mathrm{~cm}^{-1}$ which are due to the interaction of the Brønsted acid sites with pyridine forming pyridinium ion. The Lewis acidic interaction of $\mathrm{Fe}^{3+}$ was also observed at 1457 $\mathrm{cm}^{-1}$. These results gave qualitative information on the acidic sites. Acid-base titrations using Hammett indicators having different $\mathrm{H}_{0}$ values provided with 


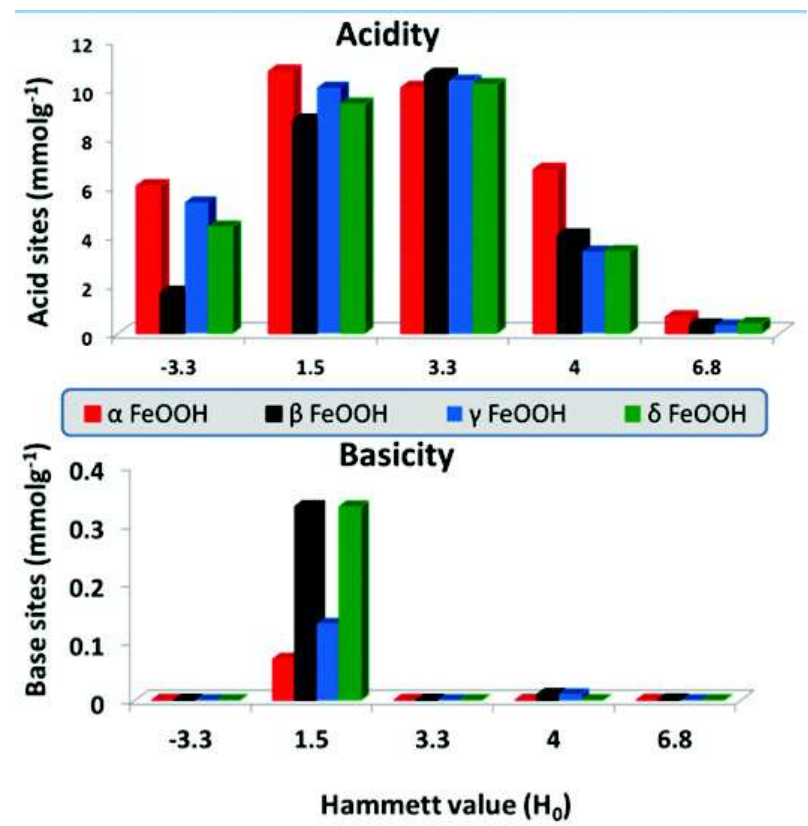

Fig. 5: Hammett titration data for the FeOOH polymorphs showing acid and base sites

the strength of acidic and basic sites on $\mathrm{FeOOH}$ polymorphs (Fig. 5). The acidity value is represented as the number of acidic sites $\left(\mathrm{mmolg}^{-1}\right)$ whose acid strength is equal to or less than the $\mathrm{H}_{0}$ value (of the indicator) and the basicity value as the number of basic sites $\left(\mathrm{mmolg}^{-1}\right)$ whose base strength is equal to or greater than the $\mathrm{H}_{0}$ value (of the indicator). Acidity and basicity are tabulated on a common $\mathrm{H}_{0}$ scale in the Fig. 3. A low $\mathrm{H}_{0}$ value was indicative of a strong acid sites whereas high $\mathrm{H}_{0}$ value represented a strongly basic site. The polymorphs showed a high number of acid sites of various strengths $\left(\mathrm{H}_{0}=-3.3,1.5,3.3\right.$, $4.0,6.8)$. The numbers of acid sites were comparatively higher than the number of basic sites. All the polymorphs showed a higher percentage of acid sites with $\mathrm{H}_{0}=1.5 \& 3.3$. This showed the $\mathrm{FeOOH}$ polymorphs are moderately acidic. As expected from the catalysis data $\alpha-\mathrm{FeOOH}$ showed high acid value and a low base sites as it gave the acid catalyzed product in high yield. All other polymorphs showed moderately strong base sites as well. However, the base site density was less as compared to acid sites.

\section{Challenges and Opportunities}

One of the important challenges in the use of $\mathrm{MOOH}$ is its preparation. Since MOOH exist in polymorphs, synthesizing a pure polymorph invariably includes presence of impurities from its other polymorph. Hence the conditions needed for their synthesis must be careful. As MOOH as metastable intermediates, they tend to transform into their corresponding oxides and lose their active surface hydroxyl groups when subjected to temperatures above $350-400^{\circ} \mathrm{C}$. Thus, $\mathrm{MOOH}$ cannot be used for extreme high temperature reactions. Our ongoing research also involves probing similar acid-base bifunctional activity in other $\mathrm{MOOH}$ such as $\mathrm{Co}, \mathrm{Al}, \mathrm{Mn}$ and $\mathrm{Cr}$. We are also working on the trends in acid-base bifunctional activity inmetal hydroxides, MOOH and metal oxides. More fundamentally, it is necessary to establish the chemical equilibrium between surface $\mathrm{OH}$ and $\mathrm{O}^{-}$groups and change in the strength of catalytic activity with metals. Our group is currently focusing on the spectroscopic technique to monitor the surface concentration of $-\mathrm{OH}$ and $\mathrm{O}^{-}$and their role in the catalytic sequence.In spite of these challenges $\mathrm{MOOH}$ can serve wonderfully well and provide great activity for organic transformations where the temperatures do not exceed the degradation temperature of $\mathrm{MOOH}$. An interesting idea is to combine different catalytic sites such as redox, hydrogenation, acidic, basic properties onto the same MOOH platform for a sequential organic transformation involving oxidation, condensation and coupling reactions. It would also be interesting to probe the synthesis of mixed $\mathrm{MOOH}$ where doping a heavier metal ion in a $\mathrm{MOOH}$ matrix could alter the geometric and electronic properties and use them for catalyzing industrially important oxidations.

\section{Heterogeneous Catalysts with Isolated Active Sites}

Apart from new multifunctional $\mathrm{MOOH}$ catalysts, we worked on developing aeffiecient synthesis strategy to prepare advanced catalysts. Porous materials have been conventionally used as supports for active metals and metal oxides. The role of porous materials in such cases is inactive except for the prevention of agglomeration of active metal catalysts supported on them by sintering at high temperatures. Although metal components are generally finely dispersed on the porous supports, only a small portion is actually involved in catalysis. Heterogeneity in metal size and shape produces difference in reactivity among the metal particles affecting the efficient utilization of metal active sites and thus reduces selectivity toward 
a specific product. Size reduction of metal particles partially overcomes such heterogeneities, in addition to benefiting the performance of catalysts due to lowcoordination environment of metal centers, quantum size effects and enhanced metal-support interactions. Recent theoretical and experimental studies have shown that sub nanometer-sized metal clusters can sometimes exhibit better catalytic activity than thenanometer-sized catalysts (Lei et al., 2010, Qiao et al., 2009, Turner et al., 2008, Kaden et al., 2009). There have been recent research efforts to decrease the size of the active metal or oxide component down to the extent of isolated single atom or ion level (Yang et al., 2013). Porous materials containing isolated metal active sites are an emerging class of catalysts due to unique reactivity (He and Antonetti, 2002). Synthesis of such porous materials containing isolated metal active sites is challenging as there is a high tendency to the formation of nanoparticle due to the aggregation of isolated atoms.

Titanium containing silicate (TS-1) catalysts, where $\mathrm{Ti}^{4+}$ substitutes $\mathrm{Si}^{4+}$ of crystalline silicates is a remarkable catalyst for the epoxidation reactions (Taramasso et al., 1983). The occurrence of a uniform and homogeneous distribution of $\mathrm{Ti}^{4+}$ active sites in silica matrix has been shown to be essential for the performance of the catalyst (Saikia et al., 2007). The potential of Ti- substituted mesoporous molecular sieve to catalyze the selective oxidation of organic compound was realized by its successful incorporation in different mesoporous silica framework like SBA-15, MCM-41, MCM-48, KIT-6 and HMS (Luan et al., 1999). Various synthesis and postsynthesis attempts have been made to synthesize Ti-substituted silica matrix. The postsynthesis path was found to be more effective over direct synthesis. However, such an approach was found to lessen the structural and textural properties of the mesoporous matrix (Fukuda et al., 2015). The sol-gel method based on the hydrolysis/condensation of alkoxide precursors, received wide attention as an efficient procedure for the synthesis of metal oxide materials and considerable effort was focused in order to obtain homogeneous samples featuring a high concentration of Ti-O-Si hetero atom linkages. These efforts concentrated on fine-tuning the hydrolysis rates for the titanium and silicon precursor alkoxides, or by use of single precursor or via prehydrolysis of the silicon precursor (Zhang et al., 2002). However, uniform distribution of the active site in silica matrix in high concentration by sol-gel chemistry was elusive. A general synthetic approach for incorporation of heteroatom on silica catalysts while maintaining single-site behavior was considered as a major advancement.

Our group explored the Ti-complexation method to produce a precursor that is stable and can condense with silica precursor for yielding a homogenously distributed isolated $\mathrm{Ti}$ centers on a silica matrix. Ethylenediamine (ED) was used as a ligand to complex with Ti, which co-condensed with hydrolysed silica precursors. ED acted as the protecting group for Ti centres and did not allow the formation of Ti$\mathrm{O}-\mathrm{Ti}$ species during the entire course of synthesis (Gupta et al., 2015). In addition, we also showed through various systematic characterization studies that the catalyst material synthesized using ED ligand did not contain any phase-separated $\mathrm{TiO}_{2}$ either in crystalline or in amorphous form for $\mathrm{Si} / \mathrm{Ti}$ ratio as high as 10 . This mesoporous $\mathrm{SiO}_{2}$ containing isolated $\mathrm{Ti}$ centres catalyst was used in the oxidation of cyclohexene, which is an industrially important chemical reaction.

The role of Ti-ED complex in the synthesis of porous $\mathrm{SiO}_{2}$ with isolated $\mathrm{Ti}^{4+}$ sites is shown in Fig. 6 . ED can form monomeric and dimeric complex with $\mathrm{Ti}$ and Si by acid-base interaction, which is more favorable with Ti. In addition, ED also triggers the hydrolysis and condensation process of metal and $\mathrm{Si}$ precursors. The formation of complex with ED prevent the formation of phase segregated $\mathrm{TiO}_{2}$. The Ti-ED complex species assemble over CTAB micelles, which when removed at high temperature will yield porous structures. The non-phase separated nature of materials were confirmed using various spectroscopic techniques. UV-vis spectroscopy and UV Raman spectroscopy showed the formation of isolated Ti centres without phase separated $\mathrm{TiO}_{2}$. Solid $\mathrm{UV}$-vis DRS spactra analyzed for different $\mathrm{Ti} / \mathrm{Si}$ ratio shown in Fig. 7. The absorption band at $220 \mathrm{~nm}$ correspond to tetrahedrally coordinated $\mathrm{Ti}$ species and band at $260 \mathrm{~nm}$ represent the multiple coordination of Ti in silica framework (Guo et al., 2012). The sample prepared without ED complex (TSC-25) showed a broad band at $330 \mathrm{~nm}$ confirming the presence of $\mathrm{TiO}_{2}$ species. Importantly, the absorption band at 330 $\mathrm{nm}$ is absent in the sample prepared by using Ti-ED precursor, which suggest majority of tetrahedral and 


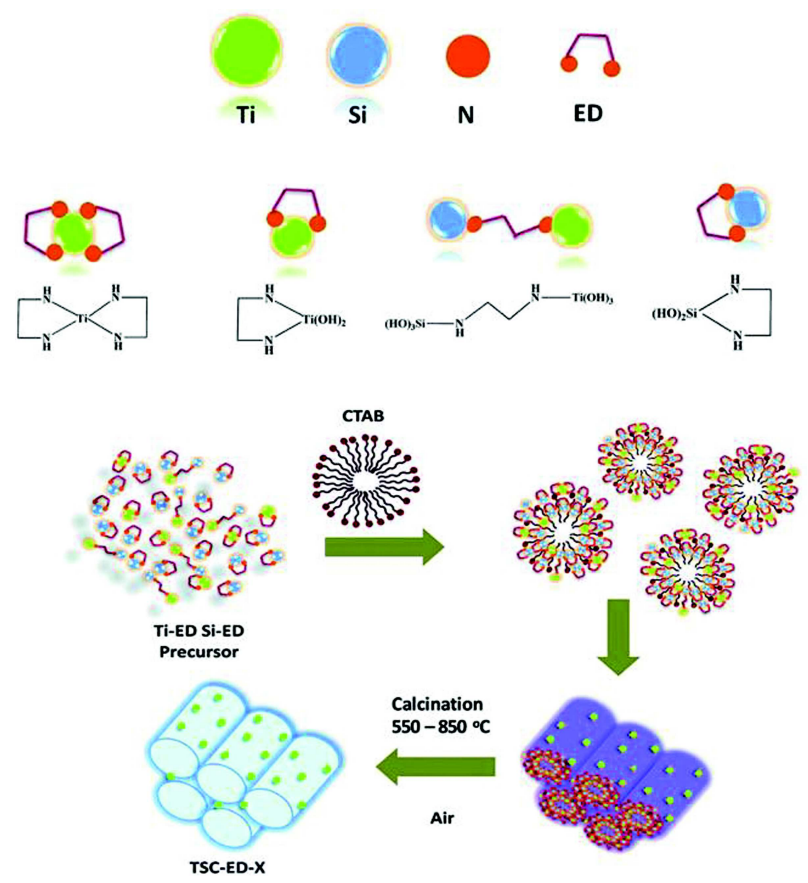

Fig. 6: The formation ED complexes of $\mathrm{Ti}$ and $\mathrm{Si}$ (Ti-ED and Si-ED) and it's self-assembly over the CTAB micelles. During calcinations in air TSC-ED-X samples with isolated $\mathrm{Ti}^{4+}$ species incorporated on $\mathrm{SiO}_{2}$ matrix is obtained. Copyright permissions are obtained

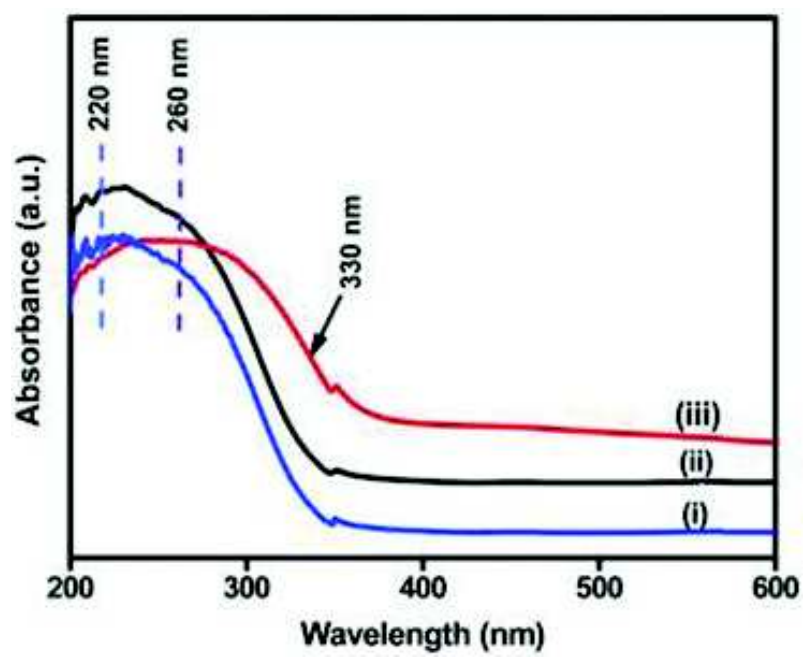

Fig. 7: UV-vis DRS spectra of (i) TSC-ED-25 (ii) TSC-ED-10 and (iii) TSC-25. Reproduced by permission of The Royal Society of Chemistry

multiple coordinated $\mathrm{Ti}$ species were present in samples prepared using ED ligand, without appearance of phase segregated $\mathrm{TiO}_{2}$.

In order to confirm the absence of amorphous $\mathrm{TiO}_{2}$ species, we analyzed the UV Raman spectra
(Fig. 8A, 8B). In all ED complex samples (TSC-ED10,25 and 40 ), band at $495 \mathrm{~cm}^{-1}$ and $1115 \mathrm{~cm}^{-1}$ are observed due to tetrahedral Ti species, while a sharp band around $690 \mathrm{~cm}^{-1}$ indicated the octahedral coordinated Ti species. These tetrahedral and multiple coordinated species are highly important in selective oxidation process. Phase separated amorphous $\mathrm{TiO}_{2}$ species which represent by $710 \mathrm{~cm}^{-1}$ band was not found in Ti-ED complex samples, which proves the importance of ED-Ti complex in the generation of homogeneous isolated active sites. Isolated Ti sites on silica support are highly active for various oxidation reactions.

The as-prepared materials were tested for the oxidation of cyclohexene using various oxidants such as $\mathrm{H}_{2} \mathrm{O}_{2}$, TBHP, $\mathrm{O}_{2}$. Ti-ED complex derived catalyst gave higher conversion and selectivity for epoxide which clearly indicated the presence of high number of isolated $\mathrm{Ti}^{4+}$ centres and high surface area. Among different Si/Ti ratio, Si/Ti 25 showed a higher activity, with $52 \%$ conversion of cyclohexene and $73 \%$ selectivity towards epoxide. At low concentration of $\mathrm{Ti}^{4+}$, number of crucial active site are less while at higher concentrations' decomposition of the $\mathrm{H}_{2} \mathrm{O}_{2}$ and TBHP oxidants occur rapidly. The catalyst showed stability for 5 cycle of oxidation reaction without drastic change in activity.

Encouraged by the success of making isolated metal catalysts by the decomposition of the metal complex, we explored extension of this method to other transition metals. Our group reported the first heterogeneous catalyst for an efficient acceptorless dehydrogenation of several bio-derived substrates such as alcohols, amines, N-heterocycles to various aldehyde, imines and quinoline derivative without using any oxidants or hydrogen acceptors Scheme 4 (Jaiswal et al., 2017; Jaiswal et al., 2016). The active catalyst Fe-L1@EGO-900 was prepared by depositing the molecular complex of iron and phenonthroline on different supports such as exfoliated graphene oxide and silica and calcined at higher temperature in inert atmosphere as per the Fig. 9 (Jaiswal et al., 2017; Jaiswal et al., 2016).

The crystalline nature and the microstructure of the catalyst was characterized using powder Xray diffraction technique (PXRD), electron microscopy (TEM and SEM). The surface chemical 

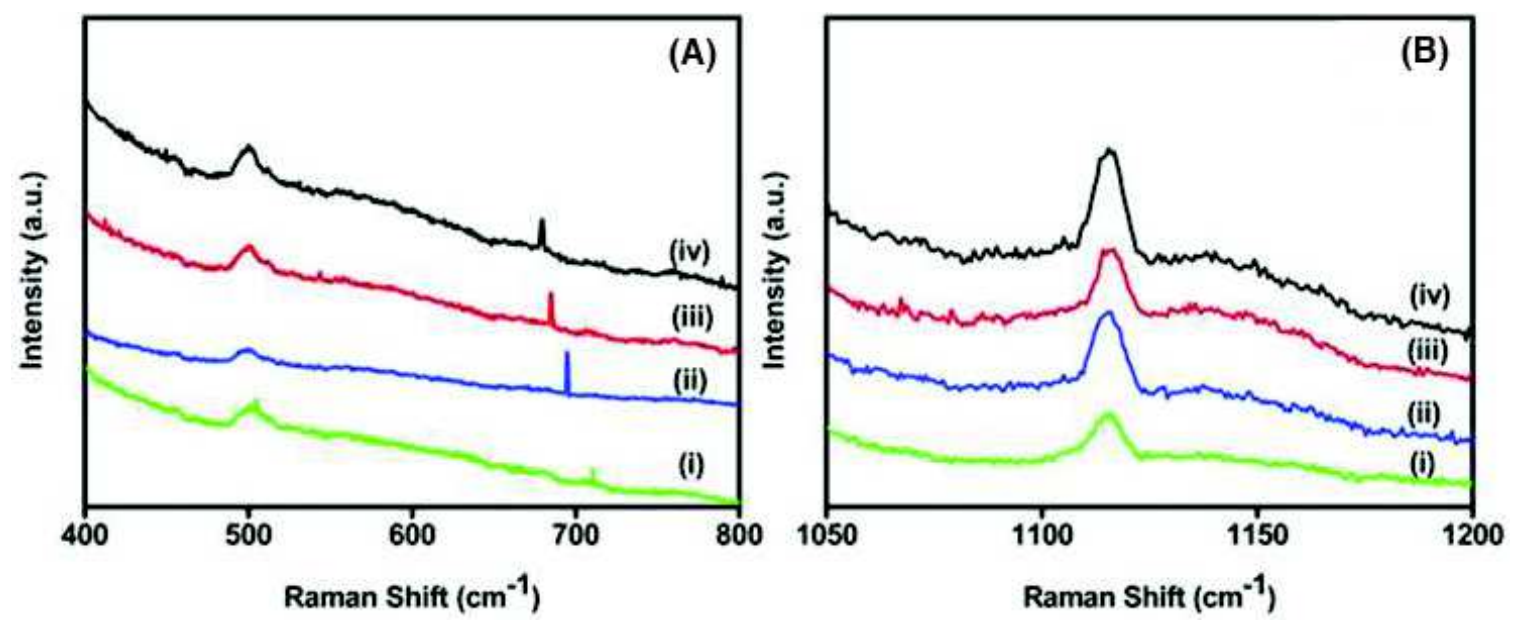

Fig. 8: UV-resonance Raman spectra of (i) TSC-25, (ii) TSC-ED-10, (iii) TSC-ED-25, and (iv) TSC-ED-40 excited at $273.8 \mathrm{~nm}$ between regions $400-800 \mathrm{~cm}^{-1}$ (A) and $1050-2000 \mathrm{~cm}^{-1}$ (B) of Raman shift. Reproduced by permission of the Royal Society of Chemistry

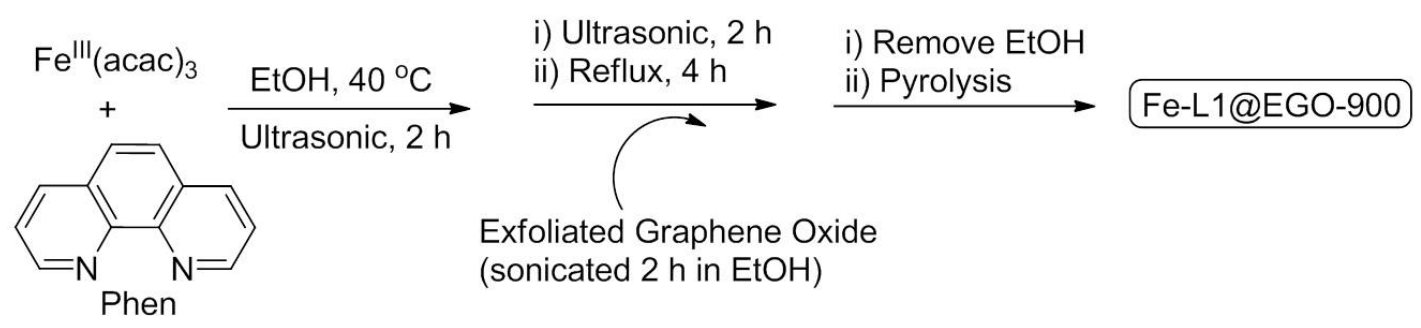

Fig. 9: Synthesis of Fe-L1@EGO-900

species were analyzed using X-ray Photoelectron Spectroscopy (XPS). Elemental composition was analyzed using Energy dispersive X-ray analysis (EDX). In PXRD data, peaks were indexed to multiple phases of $\mathrm{Fe}_{3} \mathrm{O}_{4}, \mathrm{Fe}_{3} \mathrm{~N}, \beta^{\prime \prime}-\mathrm{Fe}_{2} \mathrm{O}_{3}$ and $\mathrm{Fe}_{7} \mathrm{C}_{3}$.

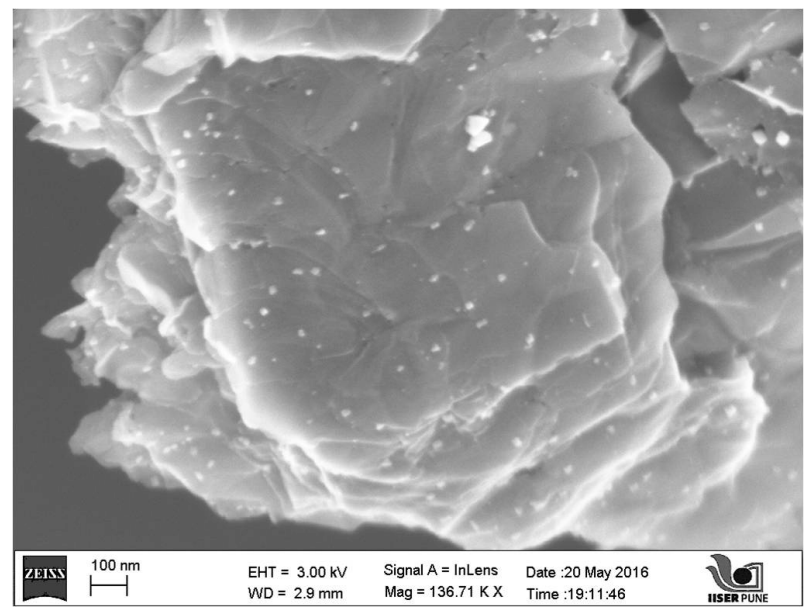

Fig. 10: SEM image of Fe-L1@EGO-900 catalyst
The morphology of the active catalyst was analyzed using scanning electron microscopy in Fig. 10. It is clear from the SEM image that iron-rich nanoparticles were well separated and supported on graphene layers. The microstructure of iron catalyst was analyzed using TEM and shown in Fig. 11. Ironrich nanoparticles were spherical in shape having size in the range of 4 to $100 \mathrm{~nm}$ with majority of the particles in the range of $11-20 \mathrm{~nm}$ as shown in the histogram (Fig. 11A). It was found that nanoparticles were having unique core-shell type of microstructure. High-resolution transmission electron microscopy (HRTEM) image of the above catalyst showed lattice fringes of $2.02 \AA$ corresponding to the $\mathrm{d}$ spacing of (211) plane of $\mathrm{Fe}_{7} \mathrm{C}_{3}$ at the core and $2.42 \AA$ corresponding to the $\mathrm{d}$ spacing of (222) plane of $\mathrm{Fe}_{3} \mathrm{O}_{4}$ phase. STEM analysis in Fig. 12 also supports presence of iron nanoparticles supported on graphene.

The iron catalyst (Fe-L1@EGO-900)was investigated for the acceptorless dehydrogenation of partially saturated $N$-heterocycles, alcohols and amine. 


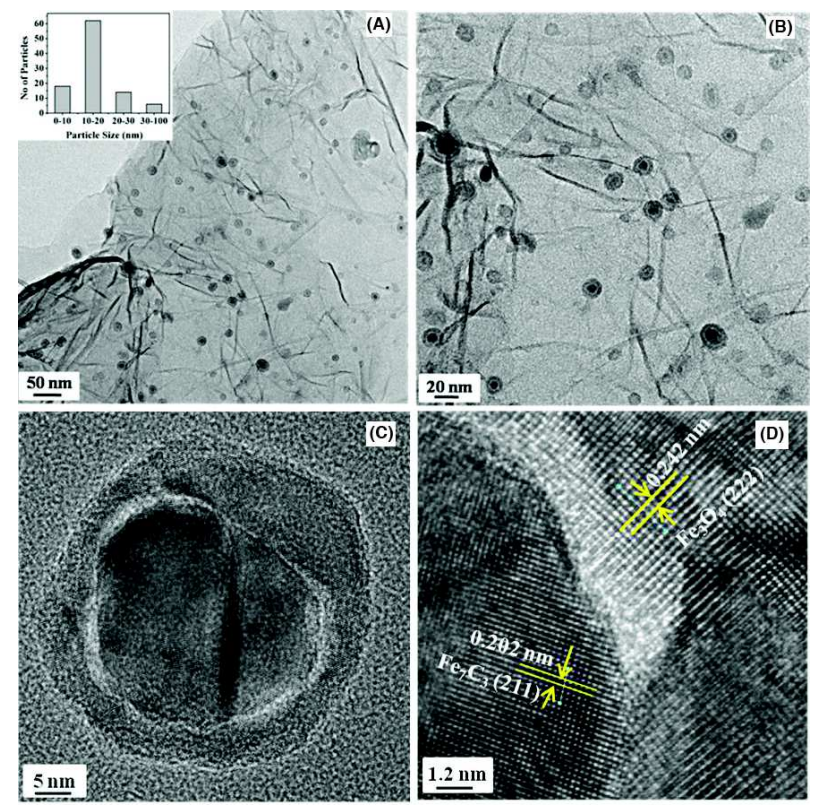

Fig. 11: Bright field TEM images of Fe-L1@EGO-900 catalyst. (A), at the scale bar $50 \mathrm{~nm}$ with inset showing an histogram of size of 100 nanoparticles, (B) at the scale bar $20 \mathrm{~nm}$, (C) a single nanoparticle at the scale bar $5 \mathrm{~nm}$ and (D) shows the high resolution lattice fringes
Dehydrogenation reactions are one of the most important organic transformations used in petrochemical and pharmaceuticals industries. Usually dehydrogenation reactions take places in the presence of strong oxidant or oxygen pressure which generates lot of copious waste (Yamaguchi et al., 2009; Balaraman et al., 2017, Xu et al., 2015). Recently, researchers have started using a sacrificial organic acceptor molecule to carry out the dehydrogenation reaction. A greener, environment friendly and efficient alternative can be to carry out the reaction without the use of acceptor molecules (Dobereiner and Crabtree 2010; Johnson et al., 2010; Wu et al., 2013; Fujita et al., 2014, Xu et al., 2015). Such a process is called acceptorless dehydrogenation in which hydrogen will be the only sole side product. Mostly noble metal based homogeneous catalysts are explored for the acceptorless dehydrogenation reaction (Dobereiner and Crabtree 2010; Johnson et al., 2010; Wu et al., 2013; Fujita et al., 2014; Xu et al., 2015). The disadvantages of such catalytic systems are high price, sophisticated synthesis of ligand, sensitive handling and poor recovery.

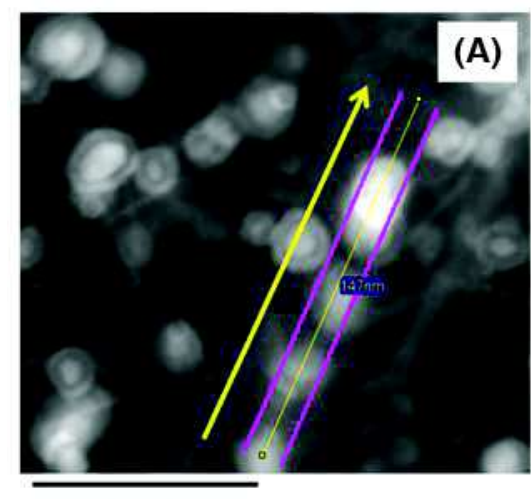

$90 \mathrm{~nm}$

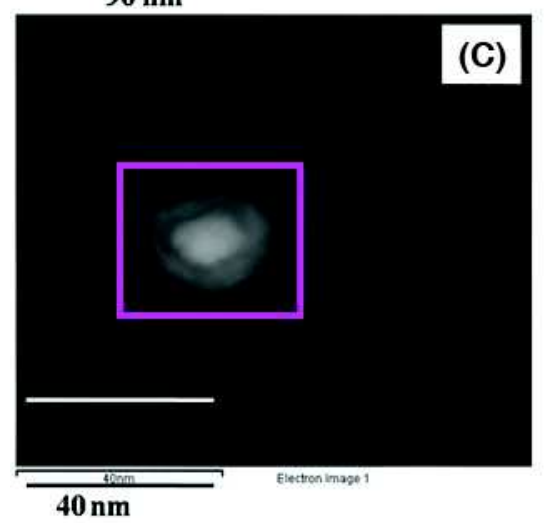

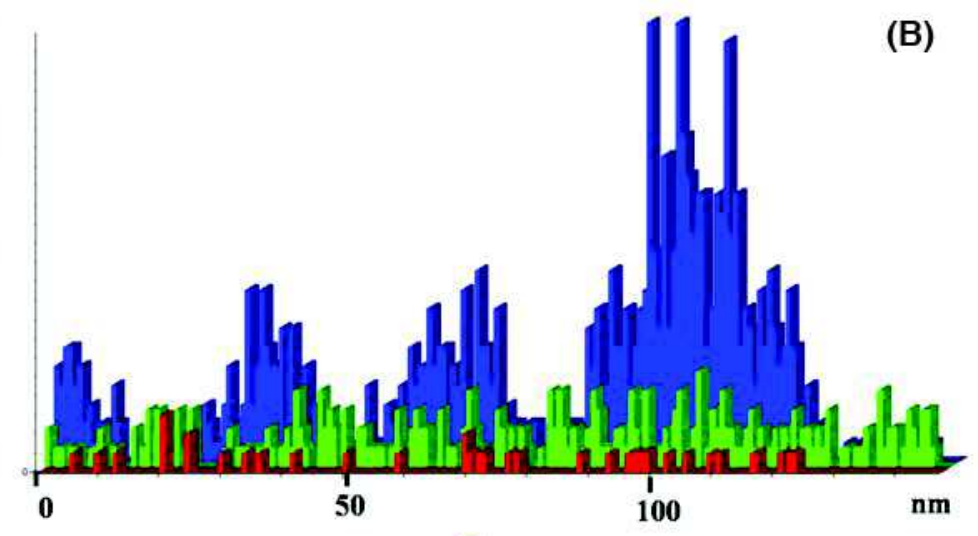

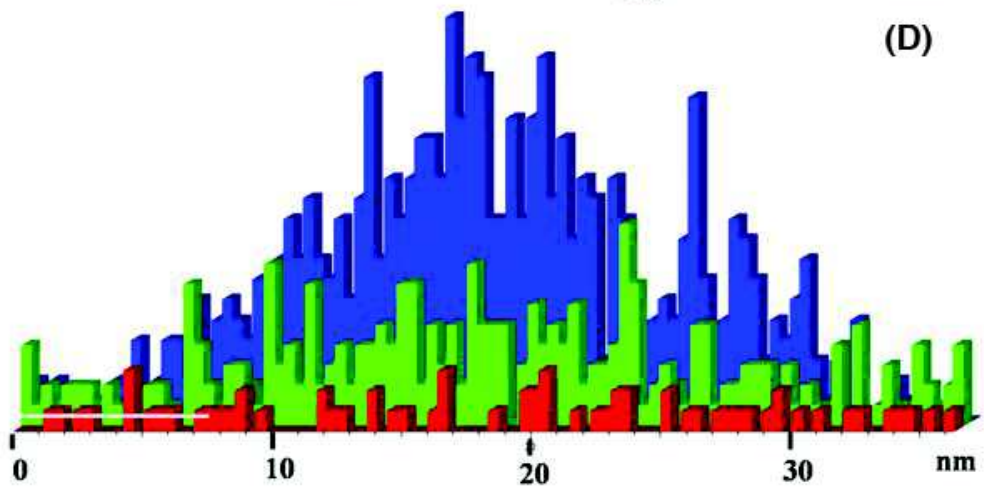

Fig. 12: (A) STEM image of Fe-L1@EGO-900 catalyst, (B) Line profile of Fe (blue), $O$ (green) and $N$ (Red) passing through the line, (C) STEM image of single particle and (D) Line profile of single iron nanoparticle passing through the particle in the given area single particle (Fe (blue), $\mathrm{O}$ (green) and $\mathrm{N}$ (red) 
Replacement of noble metals with cheaper $3 d$ transition metal-based catalyst especially that of iron, cobalt and the manganese-based heterogeneous catalyst is an area of contemporary interest (Bähn et al., 2011; Gunanathan and Milstein, 2013; Ketcham et al., 2014; Obora 2014). The challenges in this area is to improve the conversion and selectivity of the catalysts to match up those of noble metal-based catalysts. Iron-catalyzed synthetic organic transformations are highly demanding primarily due to its earth abundance.

Fe-L1@EGO-900 catalyst actively converted alcohols to aldehydes, amine to imine and partially saturated $N$-heterocycles to saturated $N$-heterocycles with the liberation of hydrogen. In order to probe the active site of the catalyst the reactivity of the active catalyst and individual pure phases were tested for the selective acceptorless dehydrogenation of alcohols. As it is clear, from the Fig. 13, only Fe-L1@EGO900 catalyst was active for the selective conversion of alcohols, individual single phases of iron are not active for the catalysis.

\begin{tabular}{|c|c|c|c|}
\hline Entry & $\begin{array}{c}\text { Catalyst } \\
(\mathbf{8 ~ m o l} \%)\end{array}$ & Conversion (\%) & Selectivity (\%) \\
\hline 1 & $\mathrm{Fe}-\mathrm{L} 1 @ \mathrm{EGO}-900$ & 95 & 93 \\
\hline 2 & $\mathrm{Fe}_{3} \mathrm{O}_{4}$ & 15 & 55 \\
\hline 3 & $\mathrm{Fe}_{2} \mathrm{O}_{3}$ & 38 & 40 \\
\hline 4 & $\mathrm{Fe}_{\mathrm{X}} \mathrm{N}$ & 15 & 80 \\
\hline 5 & $\mathrm{Fe}_{3} \mathrm{C}$ & 12 & 70 \\
\hline
\end{tabular}

Fig. 13: Table showing the conversion and selectivity of various pure inorganic phases in comparison to the mixed phase catalyst FeL1@EGO-900 in the selective dehydrogenation of alcohol

Hence, it is possible that the mixture of the phases or the interfaces of different phases of iron having specific core shell morphology is showing catalytic activity. In the similar way acceptorless dehydrogenative coupling (ADC) of alcohols with amines is also very important reaction for pharmaceutical and industry (Gnanaprakasam B.et al., 2010, Xu et al., 2010, Ho et al., 2010, Maggi et al., 2010, Li et al., 2010). We have reported ADC of alcohol and amines using a heterogeneous Fe-catalyst as per the Fig. 14.

The reaction operates under mild conditions with

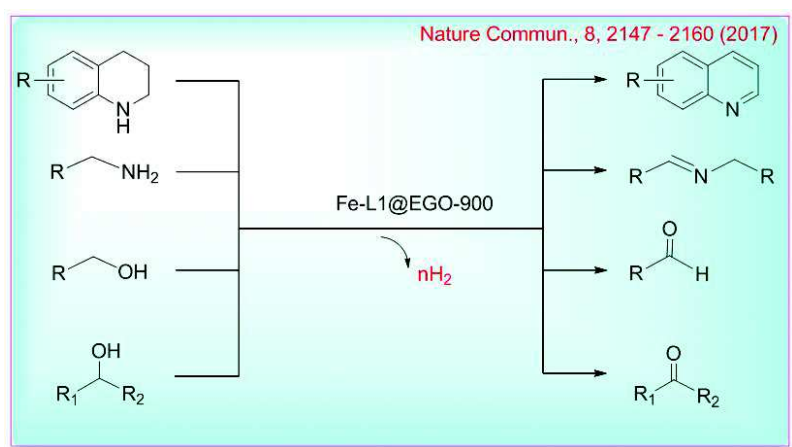

Fig. 14: Schematic representation of acceptorless dehydrogenation of alcohols, amines and $\mathrm{N}$ heterocycles

the liberation of dihydrogen and water as the byproducts. The developed ADC strategy is simple, efficient, exhibits wide functional group tolerances and can be scaled up. The molecular hydrogen generation was qualitatively analyzed by gas chromatography. Hydrogen generated during the reaction was also quantified with dual catalysis (Fig. 15).

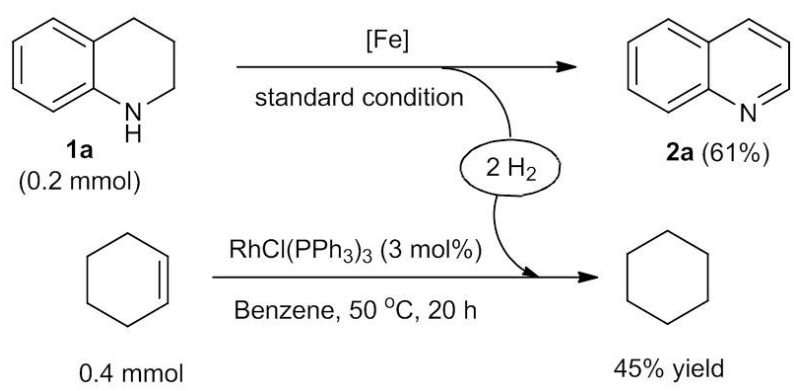

Fig. 15: Schematic showing the dual catalysis reaction where the $\mathrm{H}_{2}$ evolved from the dehydrogenation reaction was used to hydrogenate cyclohexene to cyclohexane

For Dual catalysis model reaction with tetrahydroquinoline substrate was conducted and connected with cannula to another reaction tube containing cyclohexene and a catalytic amount of Wilkinson's catalyst in benzene. After the completion of reaction, $45 \%$ of cyclohexane was produced in the second reaction tube demonstrating that the hydrogen gas was generated which is responsible for the hydrogenation of cyclohexene. The active catalyst can be magnetically separated as per given in Fig. 16. The important highlight of our work is that only the core shell structure of the complex mixed phase catalyst that is synthesized under specific conditions 


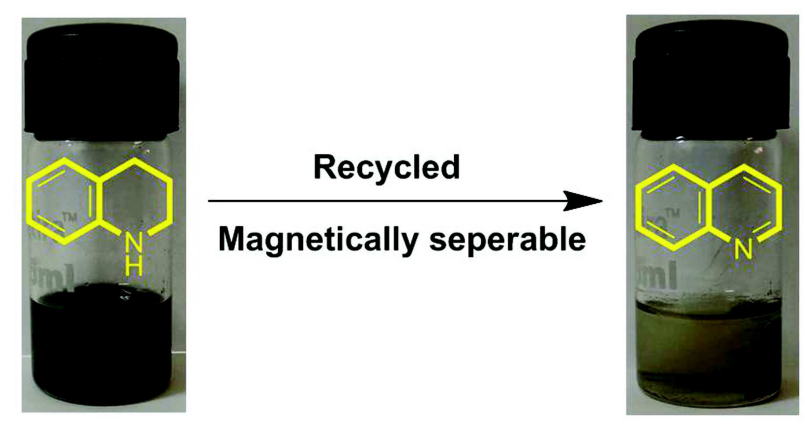

Fig. 16: Picture showing the separation of the catalyst from the reaction medium in the presence of external magnetic field

is catalytically active. A number of control experiments suggested that the inorganic iron phases when sharing the interface become catalytically active. It is till not clear if these interfaces alter the electronic structure of the surface or creates defects that are active in the catalysis of the reaction.

\section{Challenges and Opportunities}

Synthesis strategy of thermally decomposing a molecular complex of a metal yielded isolated metal atom catalysts in the case of Titanium silicate. The approach is important in the case of noble metal based catalysts, where high activity at decreased concentration of metals is highly desirable. It may be highly important to investigate and improve the activation of small molecules such as $\mathrm{H}_{2}, \mathrm{CH}_{4}$ and $\mathrm{O}_{2}$ on these catalysts so that sustainable greener catalysts may eventually be developed. Interestingly, a similar method also yielded a core shell structure with mixed phase that showed unique catalytic property. It is necessary to understand the role of ligands, concentration, surface of the support and decomposition kinetics to predict the structure that we may get. The future scope of the work would be to understand the mechanism of formation of the active core shell structure from the molecular precursor and the nature of active sites. In the future other 3d-transition metal based catalyst can also be synthesized and explored for different kind of organic transformation.

\section{$\mathrm{CO}_{2}$ Hydrogenation Using Iron-carbon Alloy Catalyst}

Another important area of research that caught our attention was the development of non-noble metal based heterogeneous catalysts for hydrogenation of $\mathrm{CO}_{2}$. The molecular transformation of $\mathrm{CO}_{2}$ into valueadded products has fascinated researchers for a long time (Arakawa et al., 2001; Jagadeesan et al., 2015). In particular, conversion of $\mathrm{CO}_{2}$ to hydrocarbons by catalytic hydrogenation will help in producing carbon neutral fuels, thus addressing both environmental pollution as well as energy shortage. However, hydrogenation of $\mathrm{CO}_{2}$ can produce a wide range of hydrocarbons from $\mathrm{C}_{1}$ to $\mathrm{C}_{20}$ depending on the reaction conditions. In fact, one of the major challenges in $\mathrm{CO}_{2}$ hydrogenation is the lack of selectivity in the product formation. Conversion of $\mathrm{CO}_{2}$ to lower olefins such as ethylene or propylene is considered important as they are useful as starting materials for the production of several bulk chemicals in polymer and fine chemical industries (Gao J et al., 2017).

The high temperature reactions such as $\mathrm{CO}_{2}$ hydrogenation are conventionally catalyzed by supported metal catalysts to withstand harsh reaction conditions. There are many factors concerning supports such as pore size, structure of supports, surface chemistry and metal-support interaction that can influence the performance of metal catalysts in achieving the desired selectivity of products (Corma, 1997; Melaet et al., 2014; Gupta et al., 2016). The activity and selectivity of these catalysts are sensitive to the interaction between the active metals and oxide supports. Previous studies suggested that the reduction of $\mathrm{CO}_{2}$ requires the cooperation of metal which can dissociate $\mathrm{H}_{2}$, and the metal-support interface which can activate $\mathrm{CO}_{2}$ (Rodriguez et al., 2015). Several examples can be found in literature where, nanoparticles of Fe, $\mathrm{Ru}, \mathrm{Co}, \mathrm{Rh}$, Ir, Ni, Pd, Pt supported on $\mathrm{SiO}_{2}, \mathrm{TiO}_{2}, \mathrm{Al}_{2} \mathrm{O}_{3}, \mathrm{ZrO}_{2}, \mathrm{CeO}_{2}$ and mixed oxides can convert $\mathrm{CO}_{2}$ to value added products (Dorner et al., 2010; Wang et al., 2011; Drab et al., 2013). Although many catalysts like supported Fe, Co and $\mathrm{Ru}$ nanoparticles show activity in $\mathrm{CO}_{2}$ hydrogenation, activity of noble metals were superior in the reaction. Development of inexpensive heterogeneous catalysts based on $\mathrm{Fe}$ or $\mathrm{Co}$ is attractive due to competitive advantages such as low cost and earth abundance and high tolerance to impurities (Zhang et al., 2010).

Our group contributed to the iron carbon catalysts system for hydrogenation reactions and in particular $\mathrm{CO}_{2}$ hydrogenation. Our approach to this problem was inspired by the challenges that $\mathrm{CO}_{2}$ hydrogenation 
reaction conditions posed on the iron based catalysts which will be described shortly. Iron carbon alloy system is an interesting class of materials where the carbon is often found in the interstices of Fe lattice resulting in the interstitial iron carbides. The relevance of iron catalysts as a potential catalyst gained support when the search for a non-noble metal based catalysts for hydrogenation reactions intensified (Smit et al., 2008). Iron based catalysts are known to be active in Fischer Tropsch process (FTS), where the catalyst is usually a mixture of oxide, metallic and carbide phases. Extensive studies were carried out on $\mathrm{Fe}_{3} \mathrm{O}_{4}$ based catalysts for FTS was undertaken in Germany and South Africa to convert syngas to fuel grade hydrocarbons during the world war (Anderson, 1956). Iron oxide phase is responsible for water gas shift activity, while iron carbide phase is essential for chain propagation leading to the formation of hydrocarbons. The results relating to the prominent role of carbide phases in both the reaction as well as deactivation were confirmed and contradicted by several surface spectroscopic studies. However, it is well established that $\mathrm{Fe}_{3} \mathrm{O}_{4}$ forms phases of carbides such as $\mathrm{Fe}_{7} \mathrm{C}_{3}$, $\mathrm{Fe}_{5} \mathrm{C}_{2}$ and $\mathrm{Fe}_{3} \mathrm{C}$ during the course of the reaction. Various modifications were carried on iron-based catalysts that are known to catalyse both RWGS and FTS reactions. Improvement of the $\mathrm{CO}_{2}$ hydrogenation performance of $\mathrm{Fe}$ catalysts were achieved by the addition of chemical promoters, such as alkali and transition metals, and structure promoters such as $\mathrm{Al}_{2} \mathrm{O}_{3}, \mathrm{TiO}_{2}, \mathrm{CeO}_{2}$ and $\mathrm{SiO}_{2} . \mathrm{Fe}_{3} \mathrm{O}_{4}$ nanocatalysts supported on graphitic carbon have emerged as a promising class of nanocatalyst for $\mathrm{CO}_{2}$ hydrogenation in recent years (Büchel et al., 2014; Minett et al., 2014). A review article dealing with the preparation, electronic properties and catalytic performance of $\mathrm{Fe}_{3} \mathrm{O}_{4}$ /carbon nanocatalysts in the conversion of $\mathrm{CO}_{2}$ to value-added products may be found (Sun et al., 2012; Tu et al., 2015). Furthermore, the FTS reaction was found to start when the iron carbiding process was almost finished. We developed an iron carbon core shell nanocatalyst system containing pre active iron carbide and oxide phases and used it for $\mathrm{CO}_{2}$ hydrogenation reaction.

We synthesized the carbide-containing iron oxide catalyst by starting from a core shell catalyst. Although $\mathrm{Fe}_{3} \mathrm{O}_{4} @$ carbon core shell catalysts were known in the literature (Xuan et al., 2007). Several chemical routes were developed to synthesize carbon encapsulated $\mathrm{Fe}_{3} \mathrm{O}_{4}$ nanostructures. But the main disadvantage is blockage of active site by complete graphitic carbon shell, which alters the catalytic activity. $\mathrm{Fe}_{3} \mathrm{O}_{4}$ /carbon nanocatalyst reported in our work was synthesized from a precursor which formed amorphous carbon in the shell (Chen et al., 2008). During pyrolysis at a high temperature, the amorphous carbon not only diffused into the core to form a mixture of $\mathrm{Fe}_{3} \mathrm{O}_{4}$ and $\mathrm{Fe}_{5} \mathrm{C}_{2}$ core but also created a partially graphitized shell. Our synthesis protocol offered a carbon precursor shell that was reactive and formed the active phase of $\mathrm{Fe}_{5} \mathrm{C}_{2}$ during annealing by reacting with $\mathrm{Fe}_{3} \mathrm{O}_{4}$ core. A chemical composition of $\mathrm{Fe}, \mathrm{Fe}_{5} \mathrm{C}_{2}$ and $\mathrm{Fe}_{3} \mathrm{O}_{4}$ encapsulated inside partially graphitized carbon shell were necessary for better efficiency of catalytic activity in $\mathrm{CO}_{2}$ hydrogenation in terms of higher FTY and higher O/P ratio in $\mathrm{C}_{2}-\mathrm{C}_{4}$ range of hydrocarbons. The carbon shell also prevented the rapid deactivation of the catalyst due to aggregation of particles.

$\mathrm{Fe}_{3} \mathrm{O}_{4}$ nanoparticles (IO NPs) was coated with a shell of amorphous carbon derived from the hydrothermal treatment of aqueous solution of glucose to form IO@aC-1 nanoparticles (Fig. 17). The as synthesized IO@aC-1 was heated in argon atmosphere at $550{ }^{\circ} \mathrm{C}$ to form $\mathrm{IO} @ \mathrm{gC}-1$ (where ' $\mathrm{g}$ ' refers to the graphitization of amorphous carbon shell) The synthesis method allowed control over the thickness of the carbon shell by varying the concentration of glucose solution which in turn controlled the chemical composition of the core. Additionally, size of $100 \mathrm{~nm}$ microspheres of $\mathrm{Fe}_{3} \mathrm{O}_{4}$ (IO- $\mu$ ) coated with graphitized carbon (IO- $\mu-\mathrm{gC}-1$ ) were synthesized using similar procedure. Fig. 18A shows a TEM image and inset shows the HRTEM image of an IO NP with lattice fringes of $3.5 \mathrm{~A}^{\circ}$ corresponding to the $d$ spacing of (311) planes of magnetite $\mathrm{Fe}_{3} \mathrm{O}_{4}$. The size distribution of IO NPs is represented as a histogram for 200 particles shown in Fig. 18B. The majority of particles distributed in the range of 10 to $15 \mathrm{~nm}$. Fig. $18 \mathrm{C}$, D, represent the TEM images of IO@aC-1 and IO@gC-1. The particle size distribution was not affected by hydrothermal conditions and high temperature treatment suggesting the effectiveness of carbon coating. The inset of Fig. 18C and Fig. 18D represent the HRTEM images of IO@aC-1 and IO@gC-1, where crystalline lattice fringes correspond to the $\mathrm{Fe}_{3} \mathrm{O}_{4}$ core and Black dashed lines indicate the interface of iron rich core 
(A)

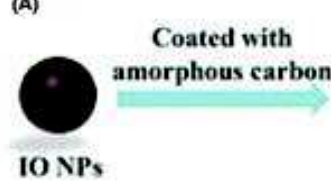

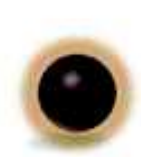

10 aC-x
Annealed at $550^{\circ} \mathrm{C}$ in Argon

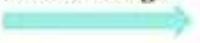

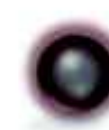

IO@gC-x

(B)
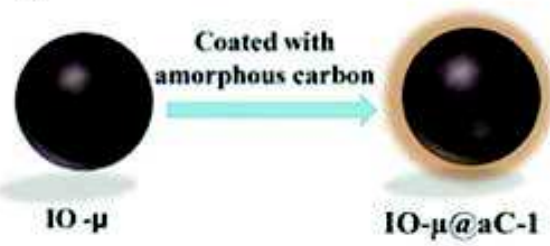

Annealed at $550^{\circ} \mathrm{C}$ in Argon

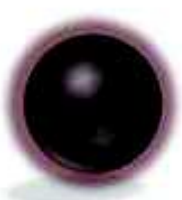

10- $\mu @ \mathrm{gC}-1$

Fig. 17: Schematic representation to explain the preparation of the samples (A) IO@gC $\mathrm{x}$, (B) IO $\mu @ \mathrm{gC} 1$ and c) cartoon representation showing the structure of a representative $\mathrm{IO} @ \mathrm{gC} \times$ sample after activation in $\mathrm{H}_{2}$

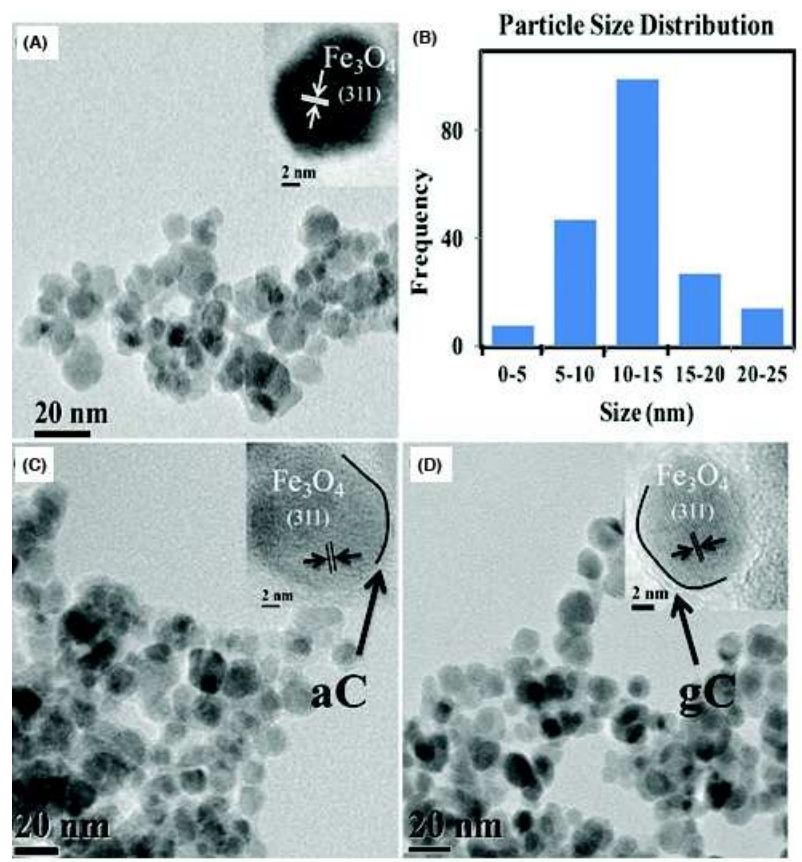

Fig. 18: (A) TEM image of IO NPs, (B) Histogram showing the size distribution of IO NPs $(\mathrm{N}=200$ nanoparticles) and (C) TEM image of IO@aC 1 and d) TEM image of IO@gC 1

and carbon shell. In Fig. 18D, the magnified image of IO@gC-1 revealed parallel layers of discontinuous graphitic carbon in the shell with a thickness of around $1-1.5 \mathrm{~nm}$.

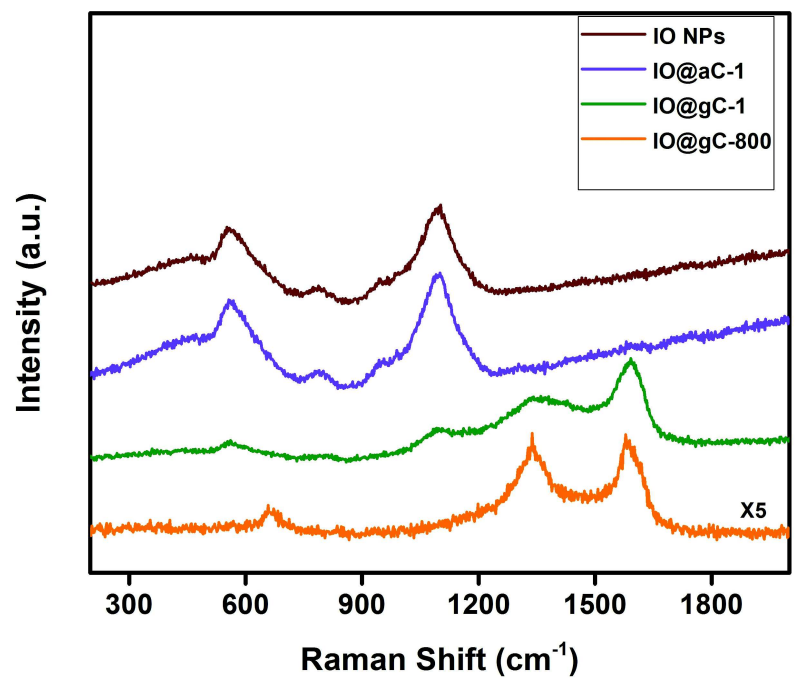

Fig. 19: Raman spectra of IO NPs, IO@aC-1, IO@gC-1and IO@gC-800

The chemical nature of carbon shell was studied by Raman spectroscopy using $514 \mathrm{~nm}$ excitation (Fig. 19). The graphitization of carbon studied by Raman spectra showed $\mathrm{G}$ band at $1593 \mathrm{~cm}^{-1}$ representing inplane vibrations of graphitic carbon. The $\mathrm{G}$ band appeared in higher intensity for IO@gC-1 than $\mathrm{IO} @ \mathrm{aC}-1$. The presence of relatively higher intense D-band at $1350 \mathrm{~cm}^{-1}$ indicated the presence of defect centres. These defects probably originate in form of micropores on the shell making the accessibility of reactant molecules to the active iron centre feasible. 


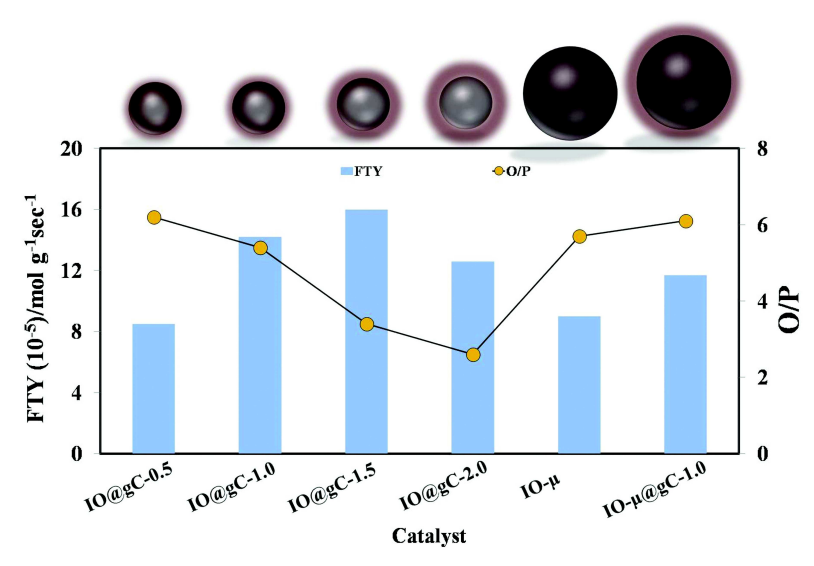

Fig. 20: Catalytic activity of IO@gC-0.5, IO@gC-1, IO@gC$1.5, \quad I O @ g C-2.0, \quad I O \mu$ and IO- $\mu @ g C-1.0 \quad$ in hydrogenation of $\mathrm{CO}_{2}$ showing $\mathrm{FTY}$ and $\mathrm{O} / \mathrm{P}$ ratio. Reproduced by permission of the publisher.

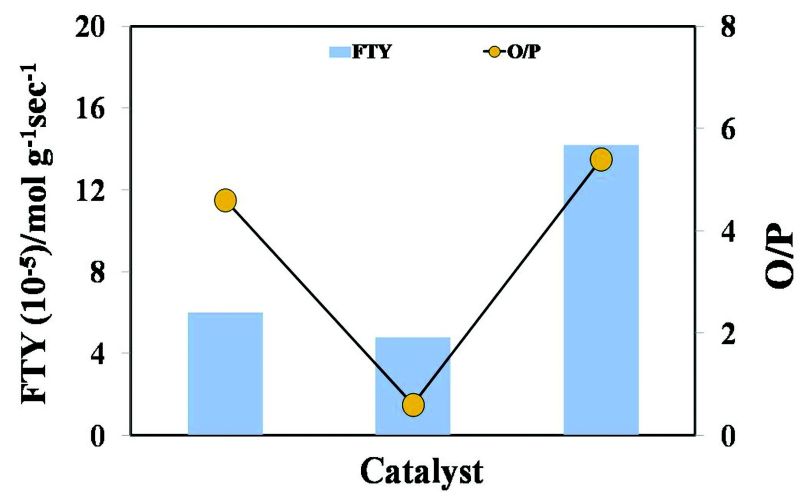

Fig. 21: From left to right: Catalytic activity of (i) IO NPs, (ii) IO@aC-1, (iii) IO@gC-1 in hydrogenation of $\mathrm{CO}_{2}$ showing $\mathrm{FTY}$ and $\mathrm{O} / \mathrm{P}$ ratio. Reproduced by permission of the publisher

Systematic catalytic studies of the hydrogenation of $\mathrm{CO}_{2}$ at $1 \mathrm{~atm}$ pressure showed that the unique nanostructure showed excellent selectivity to $\mathrm{C}_{2}-\mathrm{C}_{4}$ olefins and high thermal stability in comparison to other catalysts. The catalytic results showed that both the composition of the nanocatalysts and the extent of graphitization of the carbon shell played important roles in the catalytic performance. Partially graphitic carbon encapsulated nanoparticles (IO@gC-1) showed Iron time yield (FTY) value $11.7 \times 10^{-5} \mathrm{~mol} \mathrm{~g}^{-1} \mathrm{~s}^{-1}$, compared to bare $\mathrm{Fe}_{3} \mathrm{O}_{4}$ (IO NPs) nanoparticles ( $\mathrm{FTY}=6 \times 10^{-}$ ${ }^{5} \mathrm{~mol} \mathrm{~g}^{-1} \mathrm{~s}^{-1}$ ). FTY may be described as the number of moles of $\mathrm{CO}_{2}$ reduced per gram of catalyst in one second. With increasing the thickness of carbon shell (from IO@gC-0.5 to IO@gC-2) the olefin to paraffin selectivity decreased due to hydrogen spillover effect on carbon shell (Fig. 20, 21). Also the thickness of carbon shell plays a crucial role in catalytic activity. IO@gC-1.5 catalyst showed a highest FTY of $16 \times 10^{-5} \mathrm{~mol} \mathrm{~g}^{-1} \mathrm{~s}^{-1}$ while IO $@ \mathrm{gC}-0.5$ showed only $8 \times 10^{-5} \mathrm{~mol} \mathrm{~g}^{-1} \mathrm{~s}^{-1}$ and that of IO@gC-2 decreased to $12.5 \times 10^{-5} \mathrm{~mol} \mathrm{~g}^{-1} \mathrm{~s}^{-1}$. Increase in FTY observed with increase in carbon content upto optimum level. Further increase in carbon shell thickness results decrease in activity due to the blockage of access to Fe active sites.

\section{Challenges and Opportunities}

Converting $\mathrm{CO}_{2}$ into $\mathrm{CO}$ via RWGS has attracted considerable attention since $\mathrm{CO}$ product can be used as feedstock material for Fisher Tropsch synthesis which efficiently converts $\mathrm{CO}$ and hydrogen mixture into hydrocarbons. However, the major obstacle in the catalytic conversion from $\mathrm{CO}_{2}$ to $\mathrm{CO}$ is chemical inertness of $\mathrm{CO}_{2}$ molecule and its thermodynamic stability. Noble metal based catalyst such as Pt, Pd and Ir are commonly used for RWGS reaction. but high cost of these metals retards its application in large scale industrial process. Therefore earth abundant iron based catalyst is best candidate for ongoing process. Herein, recently we have developed iron supported graphene catalyst for the highly selective RWGS synthesis. Our catalyst is showing good to moderate conversion with more than $95 \%$ selectivity for CO, which is best fitted in state of art of catalyst for RWGS. Modern processes for selective synthesis of hydrocarbons via $\mathrm{CO}_{2}$ hydrogenation have benefitted greatly from advances in fundamental catalytic science and technology. Iron based catalyst.

\section{Conclusion}

In the last decade, major developments in surface science, characterization tools and spectroscopic tools provided an impetus to the growth of the heterogeneous catalysis in terms of fundamental understanding. Importantly, the advancements also brought to the fore, some of the major challenges and opportunities in the field. While heterogeneous catalysts are preferred for its robustness and efficiency, it is rather worrying to face situations when, occasionally the efficiency in terms of turn over number and selectivity becomes less reproducible due to heterogeneities of the sites on the catalyst. Despite realizing the strong correlations between processing 
conditions and chemical structure of the surface since long ago, the targeted synthesis of catalysts with desired active sites continues to be a major challenge. Many successful catalysts are still being discovered serendipitously or with minimal predictive knowledge to start with. It is an opportunity for researchers working in the synthesis and computational modeling to predict the chemical structure of the active sites and evolve suitable synthetic routes to them.

\section{Acknowledgment}

The author DV thanks DST for INSPIRE doctoral fellowship. The authors SG and GJ thank CSIR and

\section{References}

Anderson R B (1956) Catalysts for the Fischer-Tropsch synthesis Van Nos-trand Reinhold, New York vol. 4

Arakawa H, Aresta M, Armor J N, Barteau M A, Beckman E J, Bell A T, Bercaw J E, Creutz C, Dinjus E, Dixon D A, Domen K, DuBois D L, Eckert J, Fujita E, Gibson D H, Goddard W A, Goodman D W, Keller J, Kubas G J, Kung H H, Lyons J E, Manzer L E, Marks T J, Morokuma K, Nicholas K M, Periana R, Que L, Rostrup-Nielson J, Sachtler W M H, Schmidt L D, Sen A, Somorjai GA, Stair P C, Stults B R and Tumas W (2001) Catalysis research of relevance to carbon management: Progress, Challenges, and Opportunities Chemical Reviews 101 953-996

Bähn S, Imm S, Neubert L, Zhang M, Neumann H and Beller M (2011) The Catalytic amination of alcohols Chem Cat Chem 3 1853-1864

Balaraman E, Nandakumar A, Jaiswal G and Sahoo M K (2017) Iron-catalyzed dehydrogenation reactions and their applications in sustainable energy and catalysis Catalytic Science and Technology 7 3177-3195

Bew S P, Stephenson G R, Rouden J, Ashford P A, Bourane M, Charvet A, Dalsterin A M D, Jauseau R, Hiatt-Gipson G D and Martinez-Lozano LA (2015) Bioinspired, Base and Metal Free, Mild decarboxylative aldol activation of malonic acid half thioesters under phase transfer reaction conditions Advanced Synthesis and Catalysis 357 12451257

Büchel R, Baiker A and Pratsinis S E (2014) Effect of Ba and K addition and controlled spatial deposition of $\mathrm{Rh}$ in $\mathrm{Rh} /$ $\mathrm{Al}_{2} \mathrm{O}_{3}$ catalysts for $\mathrm{CO}_{2}$ hydrogenation Applied Catalyis A: General 477 93-101

Chen G, Xu C, Huang X, Ye J, Gu L, Li G, Tang Z, Wu B, Yang H,
UGC for their research fellowships. The author DJ sincerely thanks DST for Ramanujan Fellowship (RJN-112/2012). The authors thank collaborators Dr. C V Rode (CSIR NCL), Dr. C P Vinod (CSIR NCL), Dr. C S Gopinath (CSIR NCL), Dr. E. Balaraman (CSIR NCL) and Dr. Mrinalini Puranik (IISER Pune) for their help and useful discussions. The technical support from CSIR NCL and SAIF, IIT Bombay are gratefully acknowledged. Author DJ is a recipient of INSA young scientist medal in Chemical Sciences (2017) and he gratefully thanks INSA for the recognition.

Zhao Z, Zhou Z, Fu G and Zheng N (2016) Interfacial electronic effects control the reaction selectivity of Platinum catalysts Nature Materials 15 564-571

Chen W, Fan Z, Pan X and Bao X (2008) Effect of Confinement in carbon nanotubes on the activity of Fischer'Tropsch Iron catalyst Journal of American Chemical Society 130 9414-9419

Corma A (1997) From Microporous to mesoporous molecular sieve materials and their use in catalysis Chemical Reviews $972373-2420$

Corma A, Díaz U, García T, Sastre G and Velty A (2010) Multifunctional hybrid organic" inorganic catalytic materials with a hierarchical system of well-defined microand mesopores Journal of American Chemical Society 132 15011-15021

Cornell R M and Schwertmann U (2004) The Iron oxides: Structure, Properties, Reactions, Occurrences and Uses Wiley-VCH Verlag

Dhakshinamoorthy A and Garcia H (2014) Cascade reactions catalyzed by metal organic frameworks Chem SusChem 7 2392-2410

Diaz U, Brunel D and Corma A (2013) Catalysis using multifunctional organosiliceous hybrid materials Chemical Society Reviews 42 4083-4097

Dobereiner G E and Crabtree R H (2010) Dehydrogenation as a substrate-activating strategy in homogeneous transitionmetal catalysis Chemical Reviews 110 681-703

Dorner R W, Hardy D R, Williams F W and Willauer H D (2010) Heterogeneous catalytic $\mathrm{CO}_{2}$ conversion to value-added hydrocarbons Energy and Environmental Science 3 884890

Drab D M, Willauer H D, Olsen M T, Ananth R, Mushrush G W, 
Baldwin J W, Hardy D R and Williams F W (2013) Hydrocarbon synthesis from carbon dioxide and hydrogen: A Two-step process. Energy \& Fuels 27 6348-6354

Ertl G, Knözinger H, Schüth F and Weitkamp J (2008) (Editors) Handbook of heterogeneous catalysis Wiley-VCH Verlag GmbH\& Co. KGaAWeinheim Germany Volume 2 ISBN: 978-3-527-31241-2

Fujita K I, Tanaka Y, Kobayashi M and Yamaguchi R (2014) Homogeneous perdehydrogenation and perhydrogenation of fused bicyclic N-heterocycles catalyzed by Iridium complexes bearing a functional bipyridonate ligand Journal of American Chemical Society 136 4829-4832

Fukuda M, Tsunoji N, Yagenji Y, Ide Y, Hayakawa S, Sadakane $\mathrm{M}$ and Sano T (2015) Highly active and selective Tiincorporated porous silica catalysts derived from grafting of titanium (IV) acetylacetonate $J$ Materials Chemistry A 3 15280-15291

Gao J, Jia C and Liu D (2017) Direct and selective hydrogenation of $\mathrm{CO}_{2}$ to ethylene and propene by bifunctional catalysts Catalysis Science and Technology 7 5602-5607

Ghorbani-Choghamarani A and Tahmasbi B (2016) The first report on the preparation of boehmite silica sulfuric acid and its applications in some multicomponent organic reactions New Journal of Chemistry 40 1205-1212

Gao W, Hood Z D and Chi M (2016) Interfaces in Heterogeneous catalysts: Advancing Mechanistic Understanding through Atomic-Scale Measurements Accounts of Chemical Research 50 787-795

Gnanaprakasam B, Zhang J and Milstein D (2010) Direct Synthesis of Imines from Alcohols and Amines with Liberation of $\mathrm{H}_{2}$ Angewandte Chemie International Edition 49 1468-1471

Gunanathan C and Milstein D (2013) Applications of acceptorless dehydrogenation and related transformations in chemical synthesis Science 3411229712

Guo Q, Sun K, Feng Z, Li G, Guo M, Fan F and Li C (2012) A thorough investigation of the active titanium species in TS 1 zeolite by in situ UV resonance Raman spectroscopy Chemistry European Journal 18 13854-13860

Gupta S, Jain V K and Jagadeesan D (2016) Fine Tuning the composition and nanostructure of Fe-based core-shell nanocatalyst for efficient $\mathrm{CO}_{2}$ hydrogenation Chem Nano Mat 2 989-996

Gupta S, Vinod C P and Jagadeesan D (2015) Preparation of mesoporous titanosilicate with isolated Ti active centers for cyclohexene oxidation RSC Adv 5 92371-92377

He X and Antonelli D (2002) Recent advances in synthesis and applications of transition metal containing mesoporous molecular sieves Angewandte Chemie International Edition 41 214-229

Ho H A, Manna K and Sadow A D (2012) Acceptorless photocatalytic dehydrogenation for alcohol decarbonylation and imine synthesis Angewandte Chemie International Edition 51 8607-8610

Huang J, Shang Q, Huang Y, Tang F, Zhang Q, Liu Q and Yao T (2016) Oxyhydroxidenanosheets with highly efficient electron-hole pair separation for hydrogen evolution Angewandte Chemie International Edition 55 2137-2141

Huh S, Chen H-T, Wiench J W, Pruski M and Lin V S Y (2005) Cooperative catalysis by general acid and base bifunctionalized mesoporous silica nanospheres Angewandte Chemie International Edition 44 1826-1830

Jacobsen C J, Dahl S, Clausen B S, Bahn S, Logadottir A and Nørskov J K (2001) Catalyst design by interpolation in the periodic table: bimetallic ammonia synthesis catalysts Journal of the American Chemical Society 123 8404-8405

Jagadeesan D (2016) Multifunctional nanocatalysts for tandem reactions: A leap toward sustainability Appied Catalysis A: General 511 59-77

Jagadeesan D, Eswaramoorthy M and Rao C N R (2009) Investigations of the conversion of inorganic carbonates to methane Chem Sus Chem 9 878-882

Jagadeesan D, Joshi B and Parameswaran P (2015) Chemical utilization of $\mathrm{CO}_{2}-\mathrm{A}$ challenge for the sustainable world Resonance 20 165-176

Jagadeesan D, Sundarayya Y, Madras G and Rao C N R (2013) Direct conversion of calcium carbonate to $\mathrm{C}_{1}-\mathrm{C}_{3}$ hydrocarbons RSC Adv 3 7224-7229

Jaiswal G, Landge V, Jagadeesan D and Balaraman E (2017) Ironbased nanocatalyst for the acceptorless dehydrogenation reactions Nature Communications 8 2147-2160

Jaiswal G, Landge V, Jagadeesan D and Balaraman E (2016) Sustainable iron-catalyzed direct imine formation by acceptorlessdehydrogenative coupling of alcohols with amines Green Chemistry 18 3232-3238

Johnson T C, Morris D J and Wills M (2010) Hydrogen generation from formic acid and alcohols using homogeneous catalysts Chemical Society Reviews 39 81-88

Jolivet J P, Henry M and Livage J (2000) Metal oxide chemistry and synthesis: from solution to solid state Wiley-Blackwell

Kaden W E, Wu T, Kunkel W A and Anderson S L (2009) Electronic structure controls reactivity of size-selected Pd clusters adsorbed on $\mathrm{TiO}_{2}$ surfaces Science 326 826-829 
Khosla C (1997) Harnessing the biosynthetic potential of modular polyketide synthases Chemical Reviews 97 2577-2590

Saikia L, Satyarthi J K, Srinivas D and Ratnasamy P (2007) Activation and reactivity of epoxides on solid acid catalysts Journal of Catalysis 252 148-160

Leadlay P F (1997) Combinatorial approaches to polyketide biosynthesis Current Opinion in Chemical Biology 1 162168

Lei Y, Mehmood F, Lee, S, Greeley J, Lee B, Seifert S, Winans, R E, Elam J W, Meyer R J, Redfern P C, Teschner D, Schlogl R, Pellin M J, Curtiss L A and Vajda S (2010) Increased silver activity for direct propylene epoxidation via subnanometer size effects Science 328 224-228

Li H, Wang X, Wen M and Wang Z X (2012) Computational Insight into the mechanism of selective imine formation from alcohol and amine catalyzed by the ruthenium(II) PNP pincer complex European Journal of Inorganic Chemistry 31 5011-5020

Liu B, Liu H, Wang C, Liu L, Wu S, Guan J and Kan Q (2012), Exploration of acid-base geometric influence on cooperative activation for aldol reaction Applied Catalysis A: General 443 1-7

Luan Z, Maes E M, Heide P A W V, Zhao D, Czernuszewicz R S and Kevan L (1999) Incorporation of titanium into mesoporous silica molecular sieve SBA-15 Chemistry of Materials 11 3680-3686

Maggi A and Madsen R (2012) Dehydrogenative synthesis of imines from alcohols and amines catalyzed by a ruthenium N-heterocyclic carbene complex Organometallics 31 451455

Margelefsky E L, Zeidan R K and Davis M E (2008) Cooperative catalysis by silica-supported organic functional groups Chemical Society Reviews 37 1118-1126

Matar M S, Mirbach M J and Tayim H A (1988) Catalysis in petrochemical processes Springer Science \& Business Media

Melaet G, Ralston W T, Li C S, Alayoglu S, An K, Musselwhite N, Kalkan B and Somorjai G A (2014) Evidence of Highly Active Cobalt Oxide Catalyst for the Fischer-Tropsch Synthesis and $\mathrm{CO}_{2}$ Hydrogenation Journal of American Chemical Society 136 2260-2263

Minett D R, O’Byrne J P, Pascu S I, Plucinski P K, Owen R E, Jones M D and Mattia D (2014) Fe@CNT-monoliths for the conversion of carbon dioxide to hydrocarbons: structural characterisation and Fischer-Tropsch reactivity investigations Catalysis Science and Technology 4 33513358
Motokura K, Tomita M, Tada M and Iwasawa Y (2008) AcidBase bifunctional catalysis of silica-alumina supported organic amines for carbon-carbon bond forming reactions Chemistry European Journal 14 4017-4027

Nicolaou K C, Edmonds D J and Bulger P G (2006) Cascade reactions in total synthesis Angewandte Chemie International Edition 45 7134-7186

Obora Y (2014) Recent Advances in á-Alkylation reactions using alcohols with hydrogen borrowing methodologies $A C S$ Catalysis 4 3972-3981

Qiao B, Liu L, Zhang J and Deng Y (2009) Preparation of highly effective ferric hydroxide supported noble metal catalysts for CO oxidations: From gold to palladium Journal of Catalysis 261 241-244

Rodriguez J A, Liu P, Stacchiola D J, Senanayake S D, White M $\mathrm{G}$ and Chen J G (2015) Hydrogenation of $\mathrm{CO}_{2}$ to methanol: Importance of metal-oxide and metal-carbide interfaces in the Activation of $\mathrm{CO}_{2}$ ACS Catalysis 5 6696-6706

Smith P F, Deibert B J, Kaushik S, Gardner G, Hwang S, Wang H, Al-Sharab J F, Garfunkel E, Fabris L and Li J (2016) Coordination geometry and oxidation state requirements of corner sharing $\mathrm{MnO}_{6}$ octahedra for water oxidation catalysis: An investigation of manganite (ã-MnOOH) ACS Catalysis 6 2089-2099

Smit E D and Weckhuysen B M (2008) The renaissance of ironbased Fischer-Tropsch synthesis: on the multifaceted catalyst deactivation behavior Chemical Society Reviews 37 2758-2781

Stankiewicz A I and Moulijn J A (2000) Process intensification: transforming chemical engineering, Chemical and Engineering Progress 96 22-34

Staunton J and Wilkinson B (1997) Biosynthesis of erythromycin and rapamycin Chemical Reviews 97 2611-2630

Sun B, Xu K, Nguyen L, Qiao M and Tao F (2012) Preparation and catalysis of carbon supported iron catalysts for Fischer-Tropsch synthesis Chem Cat Chem 4 1498-1511

Taramasso M, Perego G and Notari B (1983) Preparation of porous crystalline synthetic material comprised of silicon and titanium oxides US Patent 4410501

Tietze L F (1996) Chemical Reviews Domino reactions in organic synthesis 96 115-136

Townsend C A (1997) Structural studies of natural product biosynthetic proteins Chemical Biology 4 721-730

Tu J, Ding M, Zhang Q, Zhang Y, Wang C, Wang T, Ma L and Li $X$ (2015) Design of carbon-encapsulated $\mathrm{Fe}_{3} \mathrm{O}_{4}$ nanocatalyst with enhanced performance for FischerTropsch synthesis Chem Cat Chem 7 2323-2327 
Turner M, Golovko V B, Vaughan O P H, Abdulkin P, BerenguerMurcia A, Tikhov M S, Johnson B F G and Lambert R M (2008) Selective oxidation with dioxygen by gold nanoparticle catalysts derived from 55-atom clusters Nature 454 981-983

Van Gerven T and Stankiewicz A (2009) Structure, energy, synergy, time-The fundamentals of process intensification Industrial and Engineering Chemistry Research 482 4652474

Vernekar D and Jagadeesan D (2015) Tunable acid-base bifunctional catalytic activity of $\mathrm{FeOOH}$ in an orthogonal tandem reaction Catalysis Science and Technology 5 40294038

Wang W, Wang S, Ma X and Gong J (2011) Recent advances in catalytic hydrogenation of carbon dioxide. Chemical Society Reviews 40 3703-3727

Wu J, Talwar D, Johnston S, Yan M and Xiao J (2013) Acceptorless dehydrogenation of nitrogen heterocycles with a versatile iridium catalyst Industrial Engineering and Chemical Research 52 6983-6987

Xu C, Goh L Y and Pullarkat S A (2011) Efficient iridiumthioether-dithiolate catalyst for â-alkylation of alcohols and selective imine formation via $\mathrm{N}$-alkylation reactions Organometallics 30 6499-6502
Xu L, Li C, Zhang K and Wu P (2014) Bifunctional tandem catalysis on multilamellar organic-inorganic hybrid zeolites ACS Catalysis 4 2959-2968

Xu R, Chakraborty S, Yuan H and Jones W D (2015) Acceptorless, reversible dehydrogenation and hydrogenation of $\mathrm{N}$ heterocycles with a cobalt pincer catalyst ACS Catalysis 5 6350-6354

Xu Z, Yu J and Jaroniec M (2015) Efficient catalytic removal of formaldehyde at room temperature using AlOOHnanoflakes with deposited Pt Applied Catalysis B: Environmental 163 306-312

Yamaguchi C, Ikeda Y, Takahashi and Fujita K I (2009) Homogeneous catalytic system for reversible dehydrogenation-hydrogenation reactions of nitrogen heterocycles with reversible interconversion of catalytic species Journal of Americal Chemical Society 131 84108412

Yan D, Li Y, Liu Y, Zhuo R, Wu Z, Geng B, Wang J, Ren P, Yan P and Geng $Z$ (2014) Synthesis and electrochemical properties of multilayered porous hexagonal $\mathrm{Mn}(\mathrm{OH})_{2}$ nanoplates as supercapacitor electrode material Materials Letters 136 7-10

Yang X-F, Wang A, Qiao B, Li J, Liu J and Zhang T (2013) Singleatom catalysts: A new frontier in heterogeneous catalysts Accounts of Chemical Research 46 1740-1748. 